Article

\title{
Graphite-Cement Paste: A New Coating of Reinforced Concrete Structural Elements for the Application of Electrochemical Anti-Corrosion Treatments
}

\author{
Miguel-Ángel Climent *, Jesús Carmona ${ }^{\dagger}$ and Pedro Garcés ${ }^{\dagger}$ \\ Civil Engineering Department, University of Alicante, P.O. Box 99, 03080 Alicante, Spain; jcarmona@ua.es (J.C.); \\ pedro.garces@ua.es (P.G.) \\ * Correspondence: ma.climent@ua.es; Tel.: +34-96-590-3707 \\ + These authors contributed equally to this work.
}

Academic Editor: Paul Lambert

Received: 31 May 2016; Accepted: 15 July 2016; Published: 28 July 2016

\begin{abstract}
This paper reviews research carried out towards the development of a novel conductive coating for reinforced concrete structures in order to enable the application of electrochemical anti-corrosion treatments. The coating is composed of a hardened paste containing graphite powder and cement. The applied techniques were electrochemical chloride extraction (ECE), cathodic protection (CP), and cathodic prevention, as well as combined treatments such as ECE-CP. This research has demonstrated their efficiency when using the new conductive coating as an anode system. The influence of the shape of the structural elements on the performance of the electrochemical treatments was also studied. Several characteristics of the coating have been determined, such as conductivity, durability, adhesion to the concrete surfaces, and ease of application. The results demonstrate the adequacy of using this coating as the anode for anti-corrosion treatments on reinforced concrete structural elements of different shapes, for the purpose of extending service life.
\end{abstract}

Keywords: reinforced concrete; graphite-cement paste; electrochemical chloride extraction; cathodic protection; cathodic prevention

\section{Introduction}

The Multifunctional Materials and Durability research teams of the Polytechnic School of the University of Alicante have been working together to develop a research line dedicated to understanding the behavior of graphite-cement pastes as a coating for reinforced concrete structures. This development starts from the certainty that the main enemy of reinforced concrete is steel rebar corrosion, and that the triggers of this corrosion are principally carbonation and chloride ion $\left(\mathrm{Cl}^{-}\right)$ penetration into the concrete mass.

It is true that, with today's technology and the current knowledge about corrosion processes, it is possible to manufacture reinforced concrete resistant to corrosion. However, permanent or circumstantial aggressive environments will continue to exist, and this will always be the case for structures whose construction quality controls are not very demanding. It is common to find construction works of high economic and strategic value, and it is necessary to extend their service life as long as possible. To achieve this goal, it is desirable to develop new methods allowing an effective preservation of these infrastructures from the reinforcement corrosion processes. Electrochemical treatments combined with other techniques, depending on the damage degree of the structures, have proven to be the most efficient in practice. Electrochemical chloride extraction (ECE) and cathodic protection $(\mathrm{CP})$ are the most commonly used rehabilitation techniques [1-8]. All these techniques are 
based on the application of a direct electric current in order to cause an ionic transport through the concrete mass, from the rebar to the outer surface [1-3], or to create the electrochemical conditions making impossible the corrosion of steel $[9,10]$. The electric field is applied by connecting the steel bars, acting as a cathode, to the negative pole of the power source, and an anode, typically located at the outer surface, is connected to the positive pole. Some previous studies have proposed the use of conductive cement-based overlays as the anode, especially for CP treatments [11-14]. These conductive layers put on the surface of the structural element must fulfill a number of features, among which the following would seem to be particularly noteworthy: good adherence with concrete, conductivity, durability, adaptability to various surfaces of the structures to be treated, ease of application, and low cost. Undoubtedly, it is one of the most complicated elements of the system. Hence, the anode system has been and still remains today one of the most recurrent subjects of research regarding these electrochemical treatments.

The research leading this work is aimed at designing an anodic system that successfully meets the abovementioned requirements. For this purpose, the development of multifunctional materials such as the conductive cement-based ones was pursued [15-20]. The final goal consists of a paste composed of graphite powder and cement (GCP) applied as a coating on the structural element to be treated. In the early stages of this research the influence of the thickness of the GCP overlay on the ECE efficiency was studied, establishing a minimum thickness about $2 \mathrm{~mm}$ as the most suitable for these uses [21]. Then, the GCP anodes were tested on vertical reinforced concrete elements with a dimension according to real structures, in order to improve the methods of application, wetting, and electric management for ECE treatments [22]. Another part of the research was dedicated to determining how the shape and the rebar arrangement of treated elements influence the ECE efficiency [23,24]. GCP can be used in cathodic protection treatments for highly chloride contaminated concrete elements, and in cathodic prevention (CPrev) applied to other initially chloride free but subjected to salt environments $[25,26]$. Another study was carried out to assess the possibility of using the GCP anodes for the successive application of ECE and CP to elements with high chloride content [27].

One of the most significant results of this extensive research is the suitability of a GCP coating on structural elements of reinforced concrete, for the application of electrochemical protective treatments. In the case of newly constructed structures, the coating may serve as the anode of a CPrev system in order to preserve the steel rebar free of corrosion, despite being the reinforced concrete element exposed to an aggressive $\mathrm{Cl}^{-}$environment. Given the durability of GCP coatings, the treatments can be applied permanently or intermittently. In old structures already contaminated with $\mathrm{Cl}^{-}$ions, a GCP coating allows for the application of ECE or $\mathrm{CP}$, depending on the degree of contamination. With this coating even the successive application of ECE and CP is possible [27]. This combined treatment is warranted when the structure is highly contaminated and it is expected that the environment will remain aggressive (marine environment), or when its operation entails actions involving risk of contamination (use of de-icing salt in wintertime on road structures such as bridges or parking lots).

Regarding the technological characteristics of the GCP anodic overlays, they provide enough conductivity to make efficient the electrochemical treatments, an excellent adherence with the concrete because of their cementitious nature, and an easy application by spraying or by hand. They have an adequate capacity of moisture retention of the electrolyte, enough durability for the application of successive treatments, and a much lower cost than those of other generally employed anode systems, such as the activated titanium mesh anode.

\section{Materials and Methods}

The body of research is composed of the following studies:

- Case Study 1: Competency of a GCP anode system versus a reference anode system (mesh of $\mathrm{Ti}-\mathrm{RuO}_{2}$ ), in applying ECE on pillar-size structural reinforced concrete elements.

- Case Study 2: Differences in the shape effect of the structural element during ECE application between both abovementioned types of anode systems. 
- Case Study 3: Ability of GCP anode system to apply CP, CPrev, and combined ECE-CP treatments.

\subsection{Materials and Methods Used in Case Studies 1 and 2}

\subsubsection{Reinforced Concrete Laboratory Specimens}

For Case Studies 1 and 2, reinforced concrete laboratory specimens were molded as structural supports $1 \mathrm{~m}$ long; three of them had a cylindrical shape with $200 \mathrm{~mm}$ diameter, and another three were $200 \times 300 \mathrm{~mm}^{2}$ prisms. The cylindrical ones were reinforced with six longitudinal rebars of $8 \mathrm{~mm}$ diameter, hexagonally arranged, including three stirrups of $6 \mathrm{~mm}$ diameter, uniformly distributed. Regarding the prism shapes, the reinforcement was composed of four rebars of $16 \mathrm{~mm}$ diameter located in the corners and four stirrups of $8 \mathrm{~mm}$ diameter. In all cases, concrete cover was $40 \mathrm{~mm}$ thick. Concrete had a composition as shown in Table 1. The water/cement ratio (w/c) was 0.6 , higher than usual in construction [28]. The reason is to obtain a porous concrete, in order to make easier the ionic transport across the concrete mass, evidencing in a clearer way the ECE efficiency difference between both types of anode systems. In order to simulate a serious $\mathrm{Cl}^{-}$contamination, $3.3 \% \mathrm{NaCl}$ was added to the mixing water. Thus, the concrete contained $2 \%$ of $\mathrm{Cl}^{-}$relative to cement mass.

The hardened concrete reached a compressive strength of $17.8 \mathrm{~N} / \mathrm{mm}^{2}$ [29], a porosity of $17.0 \%$ [30], and a bulk density of $2.16 \mathrm{~T} / \mathrm{m}^{3}$ [31].

Table 1. Dosage of the concrete for laboratory specimens.

\begin{tabular}{cc}
\hline Material & Dosage \\
\hline Portland cement & $350 \mathrm{~kg} / \mathrm{m}^{3}$ \\
w/c Ratio & 0.6 \\
Distilled water & $210 \mathrm{~kg} / \mathrm{m}^{3}$ \\
Limestone aggregate $4 / 6$ & $466 \mathrm{~kg} / \mathrm{m}^{3}$ \\
Limestone aggregate $6 / 12$ & $679 \mathrm{~kg} / \mathrm{m}^{3}$ \\
Limestone sand & $630 \mathrm{~kg} / \mathrm{m}^{3}$ \\
NaCl & $3.3 \%\left(2 \% \mathrm{Cl}^{-}\right.$relative to cement mass $)$ \\
\hline
\end{tabular}

\subsubsection{Experimental Details of the ECE Tests}

Two types of anodes were tested in this study. The reference anodic system consisted of a mesh of braided $\mathrm{Ti}^{-\mathrm{RuO}_{2}}$ wire, $1 \mathrm{~mm}$ thick. This wire is braided in diamond shapes $33 \mathrm{~mm}$ per $12 \mathrm{~mm}$. of diagonal length. The mesh was firmly attached, covering the whole vertical surface of the specimens, between two layers of absorbent synthetic fabric to keep moisture in. The electrical resistance of this mesh per unit length $(1 \mathrm{~m}$ length $\times 1.2 \mathrm{~m}$ width) is $0.041 \Omega / \mathrm{m}$. The mesh is connected to the positive pole of the electric source by a copper wire. On the other hand, the conductive graphite-cement paste (GCP) anode is the product of the hardening of a homogeneous mixture of graphite powder, Portland cement, and distilled water, as detailed in Table 2. The fresh paste is applied by spraying with a compressed air gun on the vertical specimen surfaces, forming a 2-mm thick overlay. The high water-to-solid ratio $(\mathrm{w} / \mathrm{s}=0.8)$ is necessary for meeting the fluidity requirements of the spraying application system. The dosage and thickness of the GCP anodic overlay were adopted as a consequence of the good performances shown by this anode system in recent research by the same authors $[21,22]$.

Table 2. Dosage of the graphite-cement paste.

\begin{tabular}{cc}
\hline Material & Dosage (for 5 kg of Paste) \\
\hline Portland cement & $1.39 \mathrm{~kg}$ \\
Graphite powder & $1.39 \mathrm{~kg}$ \\
Distilled water & $2.22 \mathrm{~kg}$ \\
\hline
\end{tabular}


The problem of keeping the anodic systems moist (both the $\mathrm{Ti}-\mathrm{RuO}_{2}$ mesh embedded into layers of absorbent fabric, and the GCP overlay) during the ECE treatments was overcome by using a system that consisted of a water pump and several pipes with droppers, assembled around the surface of each specimen. The circulated electrolyte was tap water. This periodic drip irrigation system ensures the right action of the electrolyte during the electrochemical procedure $[8,22]$.

Regarding the assembly of the ECE systems, one of each of the cylindrical and prismatic specimens was equipped with a conventional anode composed of a Ti- $\mathrm{RuO}_{2}$ mesh, as described previously. The system consisted of two absorbent polymeric layers housing the $\mathrm{Ti}^{-\mathrm{RuO}_{2}}$ mesh between them. Those three layers were successively and firmly set up, covering the whole exposed concrete surface of specimens (see Figure 1). In this way, the specimens were able to retain moisture and thus avoid increasing the necessary feeding voltage during the ECE process. Specimens assembled as mentioned were placed into a recipient with water in order to immerse the pump of the drip irrigation system. As for electrical connection, a protrusion was made in an extremity of the mesh to connect with the positive pole of the current source, closing the anodic circuit.

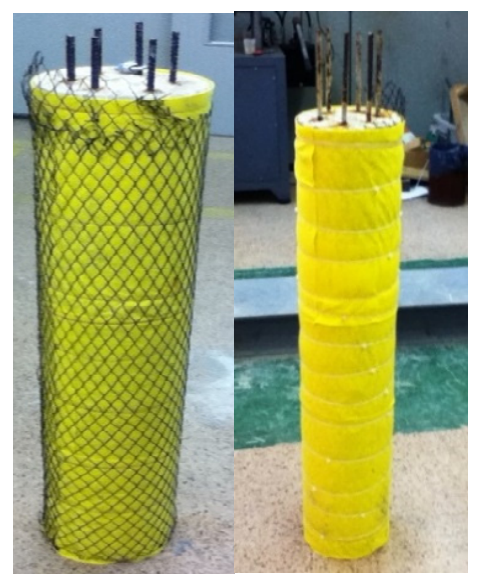

Figure 1. Anodic system composed by a Ti- $\mathrm{RuO}_{2}$ mesh embedded between two absorbent polymeric layers, wrapping a reinforced concrete specimen. Adapted from [24].

As for the rest of the specimens (one of each type), a layer of GCP was applied by spraying on all vertical surfaces. The spray was made with a compressed air gun, as a shotcrete system, forming an overlay around $2 \mathrm{~mm}$ thick. Then, the GCP overlays were moist-cured for 10 days in a curing chamber of relative humidity $>95 \%$. Finally, the GCP coating was covered by the same polymeric layer mentioned above, and the same irrigation system was also installed to ensure the presence of the electrolyte. Anodic connections were made through two interconnected graphite felt fabric strips, $4 \mathrm{~cm}$ wide, firmly attached to the GCP layer, and connected to the positive pole of the electric power source.

All specimens closed its cathodic circuit by connecting a rebar to the negative pole of the current source. The stirrups guaranteed the interconnection of all the steel reinforcement bars.

The ECE experiments were performed under galvanostatic control, i.e., under constant direct current density, which was set in the range of $2-5 \mathrm{~A} / \mathrm{m}^{2}$ relative to the exposed concrete surface of the specimen. The total electric charge density passed was of $5 \times 10^{6} \mathrm{C} / \mathrm{m}^{2}$, also relative to the exposed concrete surface. The imposed feeding voltage, which was continuously monitored, is therefore a consequence of the constant current density and the resistance of the system. This voltage tends to rise as the ECE process progresses, since the resistivity of the specimens increases. The European Standard CEN/TS 14038-2 recommends not exceeding the level of $40 \mathrm{~V}$, for safety reasons as well as to prevent damage in the anode [32]. In order to avoid exceeding the safety level, the voltage must be monitored and controlled throughout the treatment. To control the voltage evolution and any circumstances during the whole treatment, the specimens were remotely monitored by using a WIFI IP camera. 
The observed feeding voltage evolution during the ECE treatments was slightly different for the two anodic systems: the specimens tested with GCP anodic systems showed higher feeding voltages. In order to prevent reaching values over $40 \mathrm{~V}$, two types of actions were taken: the reduction of the current density values (never under $1 \mathrm{~A} / \mathrm{m}^{2}$ ), and the inclusion of pauses of the treatments. Nevertheless, in all cases the total applied electric charge density was the same: $5 \times 10^{6} \mathrm{C} / \mathrm{m}^{2}$, relative to the exposed concrete surface. It has been shown previously that the ECE efficiency is mainly governed by the applied electric charge density, with little influence of the duration of the ECE trials and of the current density [33-35]. The duration of the ECE experiments was between 325 and $350 \mathrm{~h}$.

The ECE efficiencies were calculated as the percentages of reduction of the initial chloride content. The obtention of chloride content profiles before and after the ECE trials allows for calculating the local and overall efficiencies. The $\mathrm{Cl}^{-}$profiles were obtained following RILEM's recommended procedures [36]. Cylindrical concrete cores, $95 \mathrm{~mm}$ diameter and $40 \mathrm{~mm}$ height (up to the rebar depth), were extracted before and after the ECE treatments. From these cores, concrete dust samples were obtained by grinding thin ( $2 \mathrm{~mm}$ thick) successive parallel layers to the exposed surface [36]. In this way 20 concrete dust samples were gained from each core, thus allowing the obtention of sufficiently detailed chloride content profiles. The determination of the samples' acid soluble chloride contents was carried out by potentiometric titration $[37,38]$. All the chloride content values are expressed in this work as $\% \mathrm{Cl}^{-}$relative to cement mass.

For Case Study 2, and when checking the shape effect of the structural elements on the ECE efficiencies, both circular sections (cylindrical columns) and rectangular sections (prismatic columns) were tested. In the case of the rectangular columns, two types of positions were selected for extracting the concrete cores for determining the $\mathrm{Cl}^{-}$content profiles and the ECE efficiencies (see Figure 2):

- Position number 1 in Figure 2, which corresponds to the center of the biggest face of the specimen.

- Position number 2 in Figure 2, which corresponds to the concrete cover zone over the steel rebar.
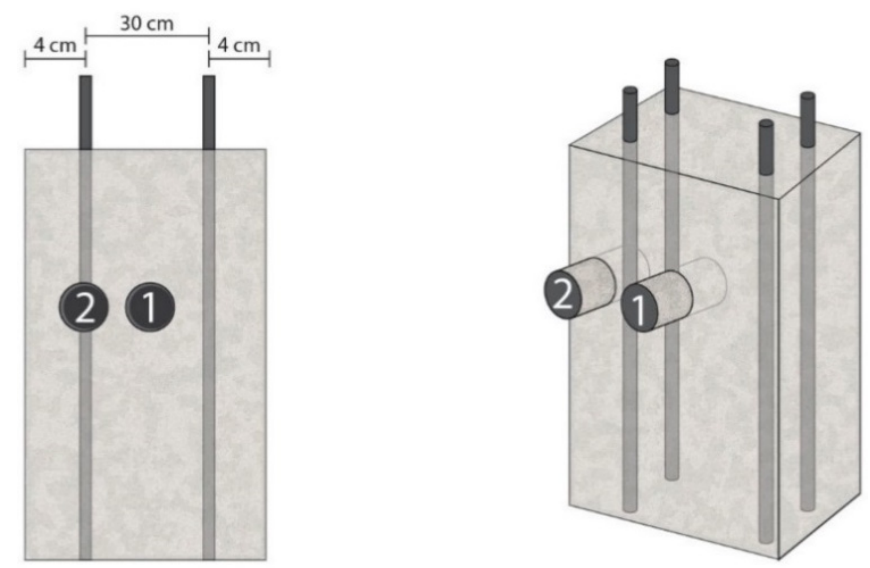

Figure 2. Extraction of two different concrete core samples on prismatic reinforced concrete specimens (Case Study 2). Point 1 is on the center of the biggest face of the specimen, and point 2 on the concrete cover, over the steel bar. Adapted from [24].

\subsection{Materials and Methods Used in Case Study 3}

The purpose of this study was to investigate the possibility of using the GCP coating as an anode for applying protective treatments of $\mathrm{CP}, \mathrm{CPrev}, \mathrm{ECE}+\mathrm{CP}$, and $\mathrm{ECE}+\mathrm{CPrev}$, to laboratory model reinforced concrete specimens. Table 3 establishes the adopted nomenclature of the specimens and the electrochemical treatments applied to each one. The specimens intended for CPrev trials (P and $\mathrm{B}$ ) were prepared with chloride-free concrete, since the CPrev treatments are designed for being continuously applied to newly constructed structures, starting from the very beginning of the structure's service life $[25,26]$. On the other hand, the rest of the specimens dedicated to testing the $\mathrm{CP}, \mathrm{ECE}+\mathrm{CP}$, or ECE+CPrev were prepared with concrete admixed with $\mathrm{Cl}^{-}$ions. The $\mathrm{CP}$ treatments 
are known to allow stopping an ongoing reinforcement corrosion process due to chlorides [25,26]. Finally, the combined treatments $(\mathrm{ECE}+\mathrm{CP}$ and $\mathrm{ECE}+\mathrm{CPrev})$ are tested here to represent situations in which a structure is exposed to an aggressive $\mathrm{Cl}^{-}$environment, and an analytical determination of concrete's $\mathrm{Cl}^{-}$content reveals an excessive value from the point of view of reinforcement corrosion. In these conditions the ECE technique is first applied to reduce the $\mathrm{Cl}^{-}$content, and afterwards a continuous protective treatment $(\mathrm{CP}$ or $\mathrm{CPrev})$ is applied to preserve the steel reinforcement in protective conditions [21,27]. It must be stressed that all specimens included in Table 3, even those that were not given any of the electrochemical treatments ( $R$ and $P$ ), were subjected to the same salting regime during the 24-week period of the $\mathrm{CP}$ or CPrev treatments: $65 \mathrm{~mL} \mathrm{NaCl} 0.5 \mathrm{M}$ was sprayed weekly onto the concrete or anodic overlay surface, in order to simulate the continued chloride contamination due to exposure to a very aggressive environment, as mentioned above.

Table 3. Nomenclature of specimens for the application of $\mathrm{CP}, \mathrm{CPrev}$, and combined treatments $\mathrm{ECE}+\mathrm{CP}$ and ECE+CPrev in Case Study 3.

\begin{tabular}{cccc}
\hline Studied Techniques & Initial $\% \mathbf{C l}^{-}$in Concrete & Reference Sample & Treated Samples \\
\hline $\mathrm{CP}$ & 2 & $\mathrm{R}$ (no electrochemical & treatment) \\
CPrev & 0 & $\mathrm{P}$ (no electrochemical & $\mathrm{A}(\mathrm{CP}$ treated) \\
treatment) & $\mathrm{B}(\mathrm{CPrev}$ treated) \\
$\mathrm{ECE}+\mathrm{CP}$ & 2 & ER (treated only with ECE) & EA (ECE+CP treated) \\
EB (ECE+CPrev treated)
\end{tabular}

\subsubsection{Reinforced Concrete Laboratory Specimens}

In this case the specimens were prism-shaped reinforced concrete elements, with dimensions of $18 \times 18 \times 8 \mathrm{~cm}^{3}$, which were reinforced by a grid of $16 \times 16 \mathrm{~cm}^{2}$ composed of six steel bars $(5 \mathrm{~mm}$ diameter) soldered symmetrically, forming squares of $5 \mathrm{~cm}$ per side, and placed $2 \mathrm{~cm}$ under the anode (Figure 3). The concrete dosage was as shown in Table 4. Two mixes were prepared: one without added chloride for preparing the specimens intended for pure cathodic prevention (CPrev) treatments, and another mix containing $2 \% \mathrm{Cl}^{-}$relative to cement mass for the specimens used in cathodic protection $(C P)$ applications or combined treatments $(E C E+C P)$ and $(E C E+C P r e v)$ (see Table 4). Once the formwork was removed, the specimens were moist-cured at $95 \%-98 \%$ relative humidity (RH) for 28 days. The characteristics of the hardened concrete were as follows: compressive strength $37.8 \mathrm{~N} / \mathrm{mm}^{2}$ [29], porosity $11.1 \%$ [30], and bulk density $2.38 \mathrm{~T} / \mathrm{m}^{3}$ [31].
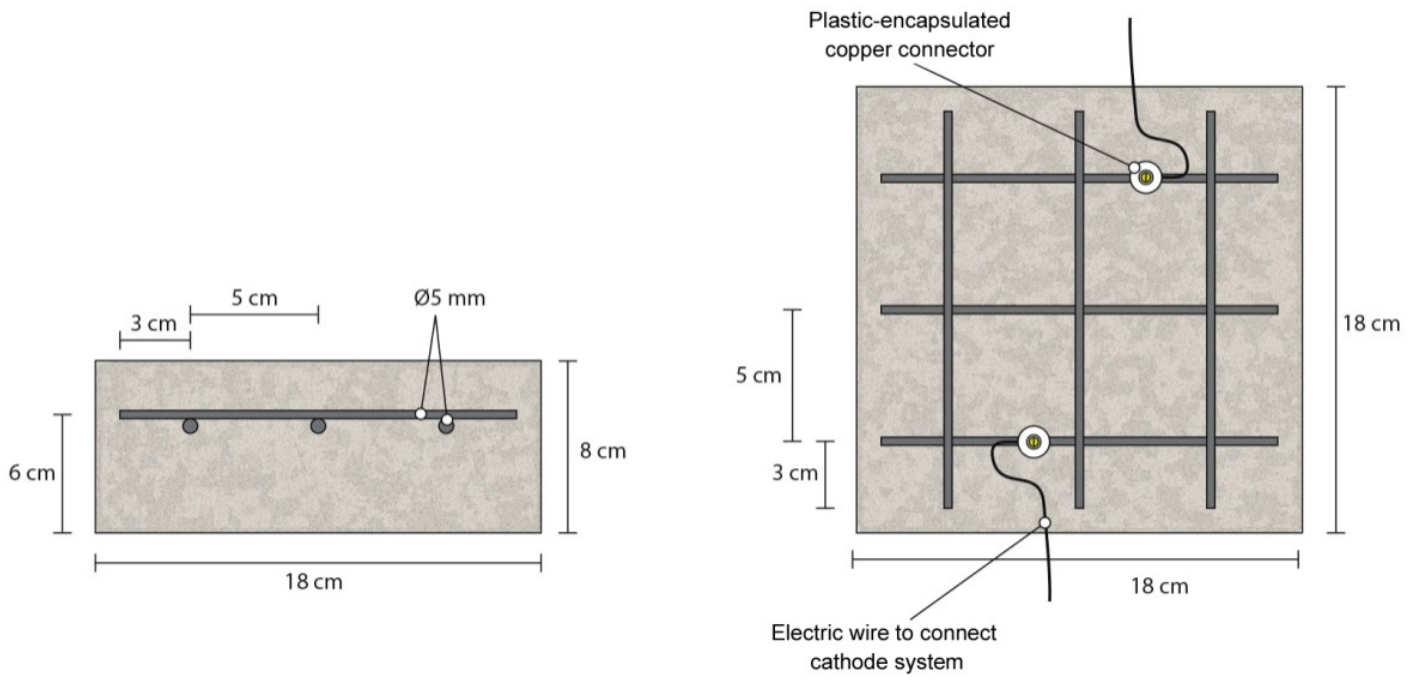

Figure 3. Sketch of reinforcement of samples and connection of the cathodic system for the specimens tested in Case Study 3. Adapted from [27]. 
Table 4. Concrete dosage of laboratory specimens for Case Study 3.

\begin{tabular}{cc}
\hline Material & Dosage \\
\hline Portland cement CEM I 42.5 R & $250 \mathrm{~kg} / \mathrm{m}^{3}$ \\
w/c Ratio & 0.65 \\
Limestone aggregate max. size $12 \mathrm{~mm}$ & $1890 \mathrm{~kg} / \mathrm{m}^{3}$ \\
Superplasticizer & $2.50 \mathrm{~kg} / \mathrm{m}^{3}$ \\
NaCl & Nil or $3.3 \%\left(2 \% \mathrm{Cl}^{-}\right.$relative to cement mass $)$ \\
\hline
\end{tabular}

Figure 3 also shows the system used for connecting the reinforcement (cathode system) to the negative pole of the electric power source, through plastic isolated copper connectors screwed to the rebar.

\subsubsection{Common Experimental Details of the Electrochemical Tests in Case Study 3}

All the electrochemical tests in this section were performed using the GCP anodic overlay. To form the anode system, a graphite-cement paste was prepared by mixing graphite powder and Portland cement at 50\%/50\% in mass. The water to solid mix ratio was 0.8 . Secondly, a 2 mm thick layer of this paste was applied on the surface of each specimen, and then all of them were moist-cured for 10 days. After that, two grooves were performed lengthwise onto the anodic overlay, without reaching the concrete surface, in order to allow both graphite rods to connect to the positive pole of the electric source. To finish up, these rods were overlaid with graphite-cement paste in order to join with the anode system perfectly, but avoiding any contact between graphite rods and concrete. A PVC receptacle was assembled on top of the samples to retain both ECE electrolyte (distilled water) and/or the dissolution used during CP or CPrev applications to simulate a continued chloride contamination (65 mL NaCl 0.5 M applied weekly), Figure 4. The ratio between the surface of concrete covered by the anodic overlay and the surface of the primary anodes (graphite rods) was 9.6; the ratio between the surface of concrete covered by the anodic overlay and the total surface of the steel bars was 1.7 (Figure 4). All current density and electric charge density values reported in this work are relative to the surface of concrete (equal to the anode surface) unless otherwise stated.

The resistivity of the graphite-cement paste was measured through the four-probe method. To this end, paste specimens were cast in $4 \times 4 \times 16 \mathrm{~cm}^{3}$ molds and moist-cured at 95\%-98\% RH for 14 days. The experimental details of the measurements can be found elsewhere [39]. The average obtained resistivity was $1.5 \Omega \cdot \mathrm{m}$.
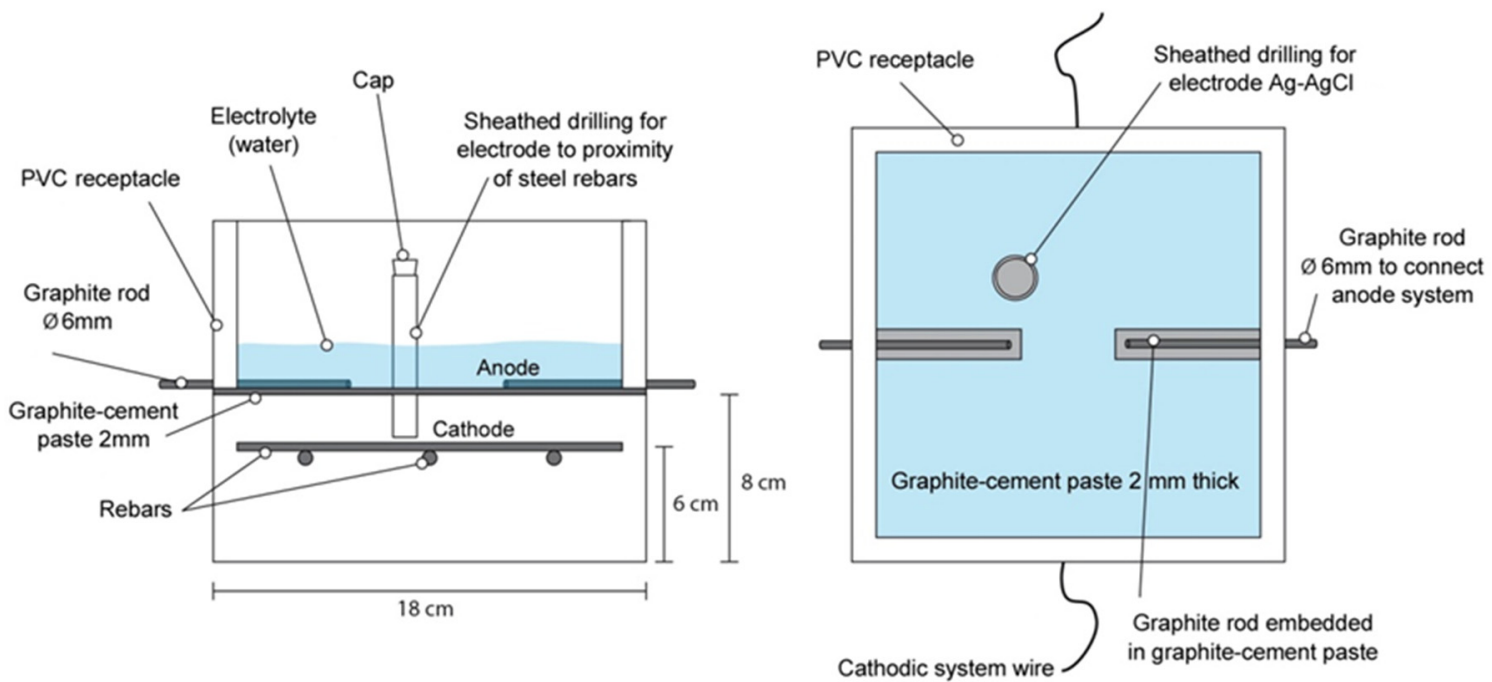

Figure 4. Sketch of specimen assembly. Adapted from [27]. 
The measurements of steel corrosion potential $\left(E_{\mathrm{corr}}\right)$ and all the single electrode potentials, were performed using $\mathrm{Ag}-\mathrm{AgCl}$ reference electrodes. These electrodes were housed in respective holes drilled from the exposed surface of the concrete specimen (that bearing the graphite-cement anode) to the vicinity of the rebar (Figure 4). For this purpose, the holes were sheathed with a plastic tube and filled with a $\mathrm{KOH} 0.2 \mathrm{M}$ solution, trying to approach the physico-chemical conditions of the concrete's inner pore solution.

In this way nine specimens were prepared, seven of them with salt in the mixing water and two without it. Two of the salted specimens were used only for determining the efficiency of the ECE process. Concrete cores were extracted from them and their chloride content profiles were determined, in one case before and in the other case after ECE. These two specimens were discarded after coring. The seven remaining specimens were intended for the tests corresponding to $\mathrm{CP}, \mathrm{Cprev}$, and the combined treatments $(\mathrm{ECE}+\mathrm{CP}$ and $\mathrm{ECE}+\mathrm{CPrev})$.

\subsubsection{ECE Treatments in Case Study 3}

Initially four of the specimens made with saline mixing water were subjected to ECE. For this purpose, the specimens were electrically connected in series by pairs to a direct current source. The relevant parameters of the ECE treatments are shown in Table 5. A low charge density was applied, only $1.5 \mathrm{MC} / \mathrm{m}^{2}$ relative to the concrete surface $\left(2.6 \mathrm{MC} / \mathrm{m}^{2}\right.$ relative to steel surface). The current source feeding voltage ( $\left.\Delta E_{\text {feed }}\right)$ was controlled at a level below $40 \mathrm{~V}$ during the processes, for safety reasons. It was necessary in this respect to interrupt the current passage two times (two pauses of $24 \mathrm{~h}$ each) along the treatment. The whole process was performed inside a fume hood to eliminate the chlorine $\left(\mathrm{Cl}_{2}(\mathrm{~g})\right)$ produced by electrochemical oxidation of the $\mathrm{Cl}^{-}$ions extracted from the concrete. When the ECE processes were finished, the $\mathrm{pH}$ values of the electrolytes were measured in order to check the acidifying effect caused by the electrochemical anodic reactions.

Table 5. Summary of ECE data for Case Study 3.

\begin{tabular}{ccccc}
\hline Initial \% $\mathrm{Cl}^{-}$ & Current Density & Initial $\Delta E_{\text {feed }}$ & Final $\Delta E_{\text {feed }}$ & Electric Charge Density \\
\hline $\begin{array}{c}2 \% \text { relative to } \\
\text { cement mass }\end{array}$ & $\begin{array}{c}2 \mathrm{~A} / \mathrm{m}^{2} \text { of concrete } \\
\text { exposed surface } \\
\left(3.4 \mathrm{~A} / \mathrm{m}^{2} \text { of steel surface }\right)\end{array}$ & $16-24 \mathrm{~V}$ & $23-22 \mathrm{~V}$ & $\begin{array}{c}1.5 \mathrm{MC} / \mathrm{m}^{2} \text { of concrete } \\
\text { exposed surface } \\
\left(2.6 \mathrm{MC} / \mathrm{m}^{2} \text { of steel surface }\right)\end{array}$ \\
\hline
\end{tabular}

ECE: Specimens with GCP as anode; Electrolyte: dammed distilled water.

\subsubsection{Application of $\mathrm{CP}, \mathrm{CPrev}$, and the Combined Treatments $\mathrm{ECE}+\mathrm{CP}$ and $\mathrm{ECE}+\mathrm{CPrev}$}

This section describes the details of the experiments carried out to demonstrate the applicability of the GCP anodes for protective treatments of $\mathrm{CP}, \mathrm{CPrev}, \mathrm{ECE}+\mathrm{CP}$, and ECE+CPrev (please refer to Table 3).

The $\mathrm{CP}$ treatments were applied with $15 \mathrm{~mA} / \mathrm{m}^{2}$ of current density (relative to concrete or anode surface) to two specimens, one of those previously treated with ECE (EA in Table 3) and the other one without prior treatment (A in Table 3). On the other hand, we applied CPrev with $2 \mathrm{~mA} / \mathrm{m}^{2}$ of current density (relative to concrete surface) to a sample previously ECE treated (EB in Table 3) and to another manufactured without salt and not ECE treated (B in Table 3). The values of the current densities relative to the steel bars' surface are $25.5 \mathrm{~mA} / \mathrm{m}^{2}$ and $3.4 \mathrm{~mA} / \mathrm{m}^{2}$ for the $\mathrm{CP}$ and Cprev treatments, respectively. The direct current source was programmed to maintain a constant current density along the whole process. Each application has its reference sample without treatment of CP or CPrev to compare the results. The reference sample for the specimens subjected to combined treatments (EA for $\mathrm{ECE}+\mathrm{CP}$, and $\mathrm{EB}$ for $\mathrm{ECE}+\mathrm{CPrev}$ ) is ER. $\mathrm{R}$ is the reference for $\mathrm{A}$, and $\mathrm{P}$ is the reference for $\mathrm{B}$.

The application of $\mathrm{CP}$ and $\mathrm{CPrev}$ consisted of two phases:

Phase 1. First 24 weeks. The aforementioned treatments $\mathrm{CP}$ and $\mathrm{CPrev}$ were continuously applied during the first 13 weeks. Then, the current was switched off for four weeks and after that 
treatments were resumed to the end. Chloride contamination was continuously applied, even during the switch-off periods.

While applying the $\mathrm{CP}$ and $\mathrm{CPrev}$ treatments, some parameters representative of the corrosion state of steel were measured in open-circuit conditions. During the first two weeks, the steel corrosion potential $\left(E_{\text {corr }}\right)$ was daily measured by means of an $\mathrm{Ag}-\mathrm{AgCl}$ reference electrode. Since the third week both the corrosion potential and the steel corrosion rate $i_{\text {corr }}\left(\mu \mathrm{A} / \mathrm{cm}^{2}\right)$ were determined weekly. The icorr measurements were taken with a Gecor6 device (Geocisa, Madrid, Spain). Gecor6 is a portable measurement unit based on the linear polarization resistance method. The equipment uses a modulation confinement technique, allowing the quantitative determination of the corrosion rate [40]. During the current passing periods the feeding voltage of each specimen, $\Delta E_{\text {feed }}$, was obtained as the potential difference between cathode and anode; and the individual anodic and cathodic potentials, $E_{\mathrm{a}}$ and $E_{\mathrm{c}}$, respectively, were measured against the reference electrode $\mathrm{Ag}-\mathrm{AgCl}$. Finally, in order to check the efficiency of CP and CPrev as maintainers of protection conditions of steel, the "100 $\mathrm{mV}$ decay" criterion was used, as is specified in ISO 12696:2012 [41]. This criterion has been also extensively employed for this purpose by several researchers [14,42]. The method consists in obtaining the four-hour potential decay ( $\Delta E_{\text {decay }}$ ) that is the difference between $E_{\mathrm{c}}^{4 \mathrm{~h}}$ (the value of $E_{\mathrm{c}}$ four hours after the current switch-off), and the instant-off cathodic potential $E_{\mathrm{c}}^{\mathrm{io}}$, which in this case was measured $1 \mathrm{~s}$ after the current switch-off. The minimum value of the four-hour depolarization must be $100 \mathrm{mV}$ for an adequate corrosion protection of steel [41]. The values of $E_{\mathrm{c}}^{\text {io }}$ were monitored with an automatic data logger able to obtain and record 500 measurements in $6 \mathrm{~s}$ after the current switch-off.

Once the 24-week processes were fulfilled, cores were extracted from all specimens of Table 3, and their respective $\mathrm{Cl}^{-}$content profiles were obtained.

Phase 2. At the end of Phase 1 it was observed that all the specimens had lost the steel protection condition, evidenced by $\Delta E_{\text {decay }}$ values lower than $100 \mathrm{mV}$. Then, it was decided to start this second phase with the objective of recovering the protection conditions of steel by adjusting the current density of the $\mathrm{CP}$ treatments. The procedure was to increase progressively the current density over four weeks, starting with a value of $20 \mathrm{~mA} / \mathrm{m}^{2}$, until the protection conditions were obtained.

Chloride content profiles were experimentally determined, following the methodology described in Section 2.1.2, for the specimens listed in Table 3, in order to understand the net effect of the electrochemical treatments on the $\mathrm{Cl}^{-}$ion uptake by the reinforced concrete specimens during the continued exposure to a very aggressive environment.

\section{Results and Discussion}

3.1. Case Study 1: Competency of a GCP Anode System versus a Reference Anode System (Mesh of Ti-RuO $\mathrm{O}_{2}$ ) in Applying ECE on Pillar-Size Structural Reinforced Concrete Elements

This section describes the results obtained in the experiments carried out to compare the ECE efficiencies obtained with the GCP anodic overlay and the classical Ti- $\mathrm{RuO}_{2}$ mesh anode, in terms of percentage of reduction of the initial $\mathrm{Cl}^{-}$content; refer to Section 2.1.

Figures 5 and 6 show the initial and final chloride content profiles, before and after ECE, together with the distributions of local efficiencies of the ECE treatment. Figure 7 shows the comparisons of the local efficiencies obtained with the two types of anodes. The averaged efficiencies along the concrete cover zone of steel ( $40 \mathrm{~mm}$ width) were $79.4 \%$ for the $\mathrm{Ti}^{-\mathrm{RuO}_{2}}$ anode, and $79.2 \%$ for the GCP anode. Another observation extracted from Figure 7 is that for both anodes the ECE process is more efficient in the zone closer to the concrete surface. These results clearly show the feasibility of using a GCP anode for ECE treatments, without losing the efficiency of the process, in comparison with the classical $\mathrm{Ti}-\mathrm{RuO}_{2}$ mesh anode, in agreement with the results of similar research [43]. 


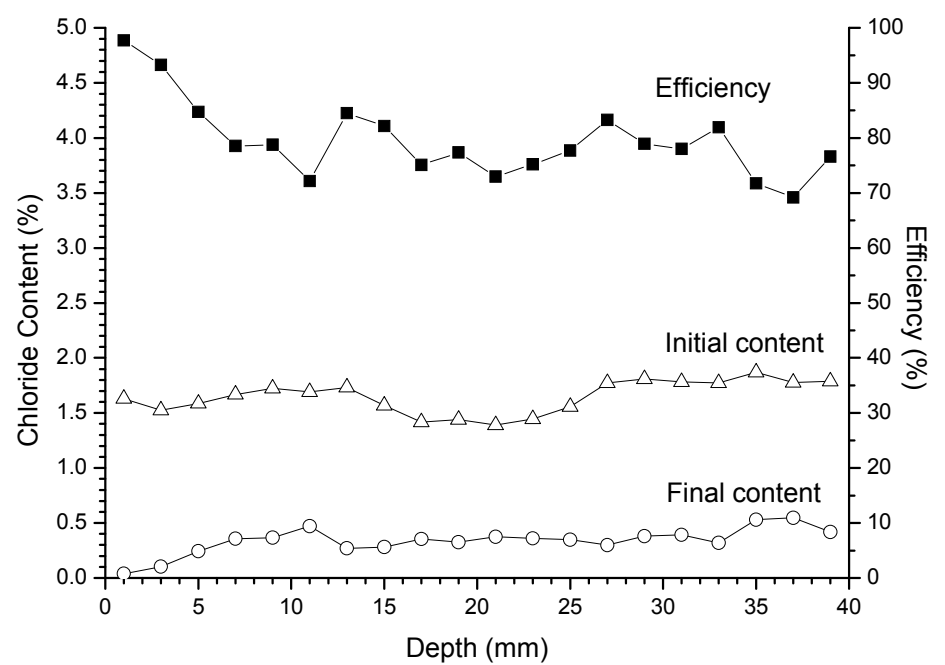

Figure 5. Chloride content profiles and ECE efficiencies using the reference anode system based on a $\mathrm{Ti}-\mathrm{RuO}_{2}$ mesh. Adapted from [22].

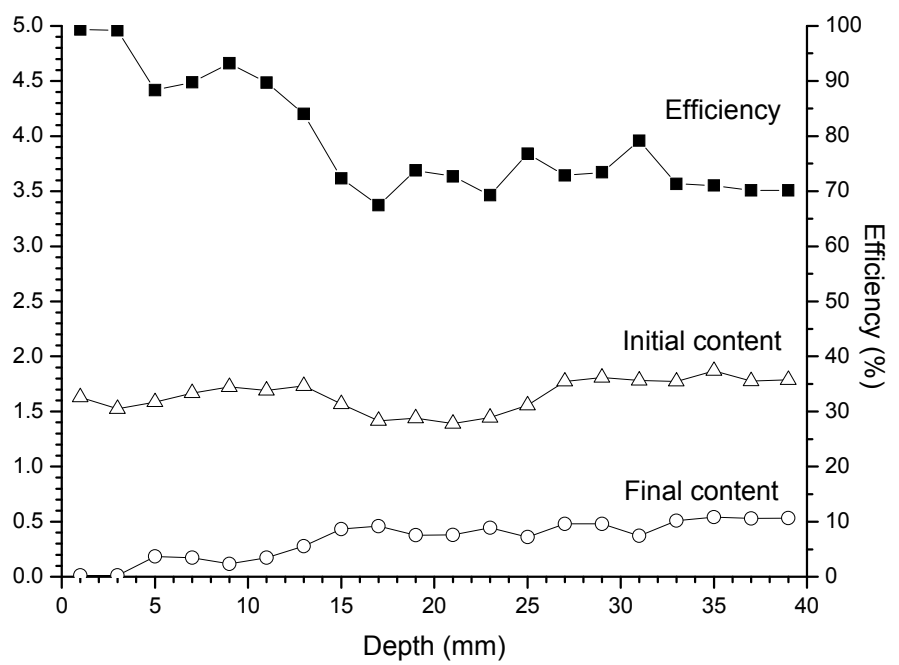

Figure 6. Chloride content profiles and ECE efficiencies using a GCP coating as anode system. Adapted from [22].

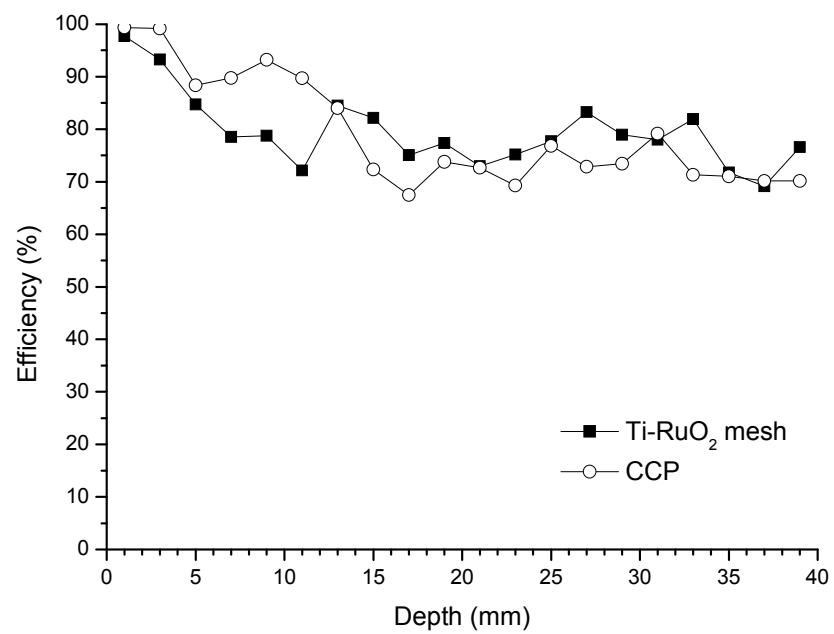

Figure 7. Compared ECE efficiencies for the $\mathrm{Ti}^{-\mathrm{RuO}_{2}}$ mesh and GCP anodes. Adapted from [22]. 
3.2. Case Study 2: Differences in the Shape Effect Structural Elements during ECE Application in Both Types of Anode Systems

In 1998 Tritthart [3] applied the concept of electric flow produced during ECE to predicting differences in the local efficiencies of ECE, due to the lack of homogeneity in the intensity of the electric field acting between the steel rebar and the external anodes. This has some consequences regarding the practical application of ECE to reinforced concrete elements. Specimens of circular section with a regular rebar distribution, coupled with an anode with a symmetric concentric distribution, can provide an isotropic electric field for the ECE treatment. Conversely, the more habitual geometry and heterogeneous rebar arrangements of rectangular section reinforced concrete elements may produce local differences in the electric field intensity between different zones of the surface of the concrete structure, thus leading to differences in the ECE efficiency (Figure 8). The aim of this section is to provide further quantitative experimental confirmation of these statements, and to evaluate the influence of the type of anode on the abovementioned anisotropic effect caused by the typical rebar arrangements in reinforced concrete elements [24]. To this end, chloride content profiles were determined both before and after ECE for reinforced concrete elements of circular sections (isotropic electric field), and rectangular sections (anisotropic electric field). For the latter, different sampling positions were selected in order to prove the mentioned effect. (Refer to Figure 2 in Section 2.1.).
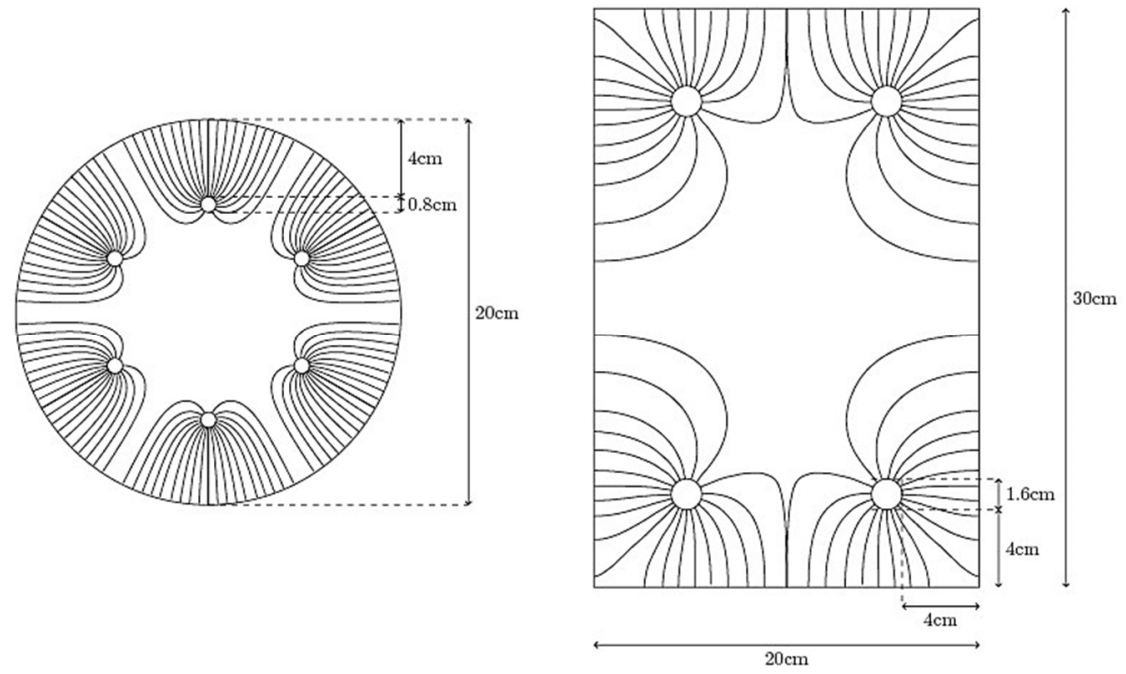

Figure 8. Different electric flow schemes during ECE application in an isotropic vertical element (circular section and regularly reinforced) and in an anisotropic vertical specimen (rectangular section and conventionally reinforced with rebar in the corners). Current streamlines, calculated using a standard finite element method, are shown. Adapted from [24].

The ECE tests in this section were performed using current density values between 2 and $5 \mathrm{~A} / \mathrm{m}^{2}$, but the electric charge density passed was of $5 \times 10^{6} \mathrm{C} / \mathrm{m}^{2}$ in all cases; both densities refer to the concrete surface. Figures 9-12 show the initial and final $\mathrm{Cl}^{-}$content profiles, together with the distributions of local ECE efficiencies through the concrete cover over steel for the specimens of a rectangular section at sampling positions 1 and 2 (refer to Figure 2).

Figures 9-12 and Table 6 gather the relevant results in relation to the shape effect of the structural element on the ECE efficiency. As for circular section specimens (chloride profiles not shown), the mean ECE efficiencies are practically equal for both anode systems. The high ECE efficiency, in either anode system and either sampling point, can be attributed to the uniformity and high density of electric flow lines established between a regular cathode (rebars uniformly distributed) and an equidistant anodic surface, as was exposed previously. 


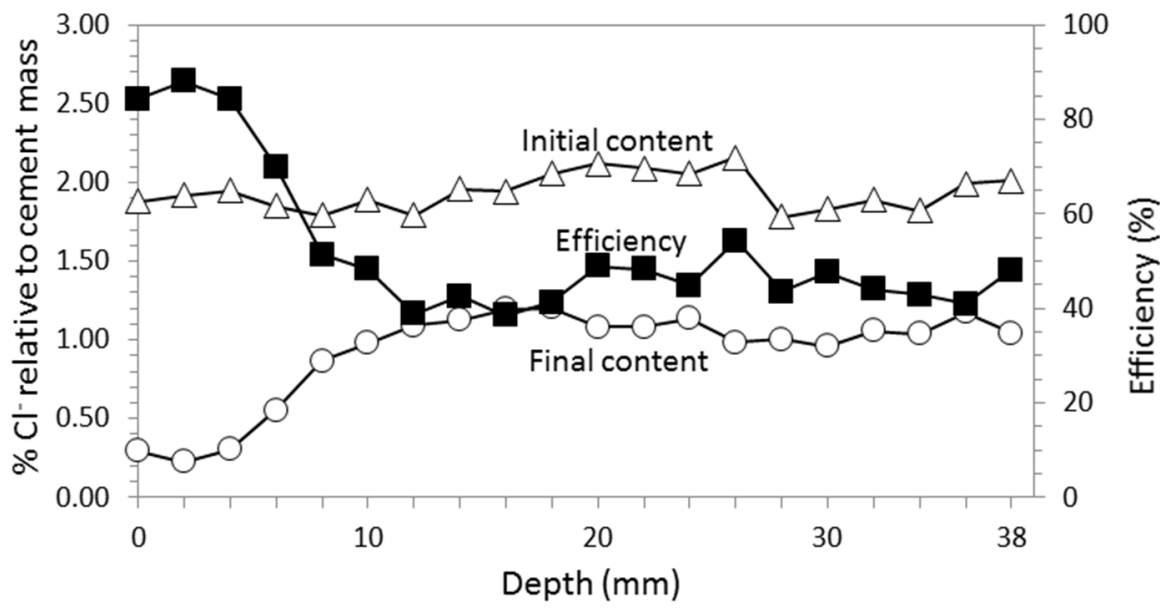

Figure 9. ECE with $\mathrm{Ti}-\mathrm{RuO}_{2}$ anode. Rectangular section reinforced concrete specimen. Core extracted in the center of the biggest face of the specimen (position 1 in Figure 2). $\mathrm{Cl}^{-}$content profiles before and after ECE and distribution of local ECE efficiencies. Adapted from [24].

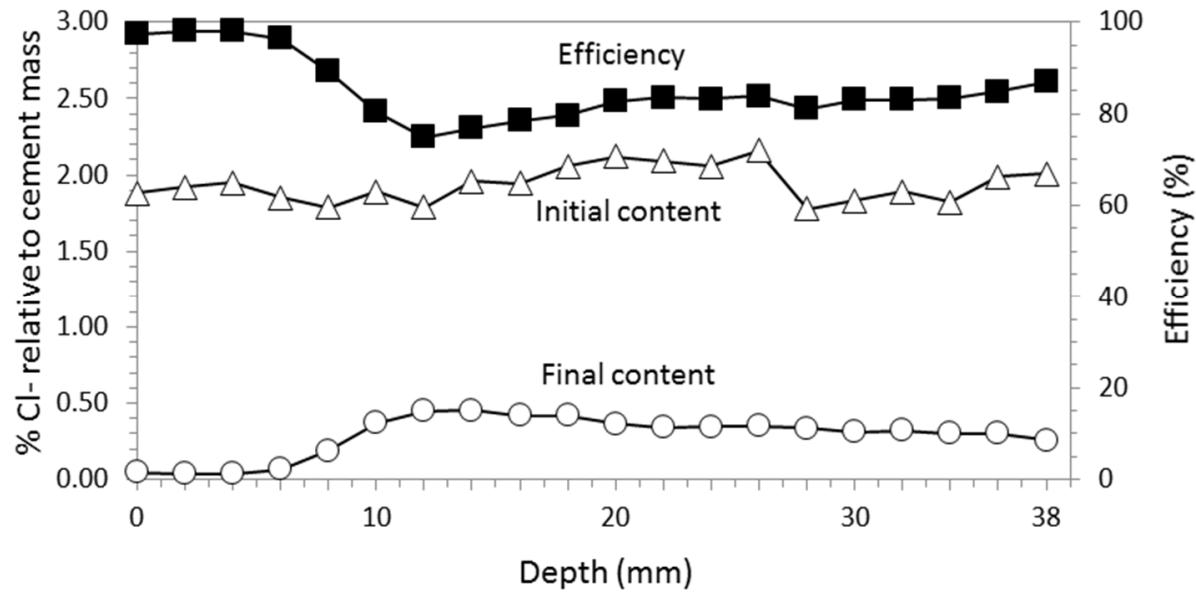

Figure 10. ECE with $\mathrm{Ti}-\mathrm{RuO}_{2}$ anode. Rectangular section reinforced concrete specimen. Core extracted in the cover zone over the steel (position 2 in Figure 2). $\mathrm{Cl}^{-}$content profiles before and after ECE and distribution of local ECE efficiencies. Adapted from [24].

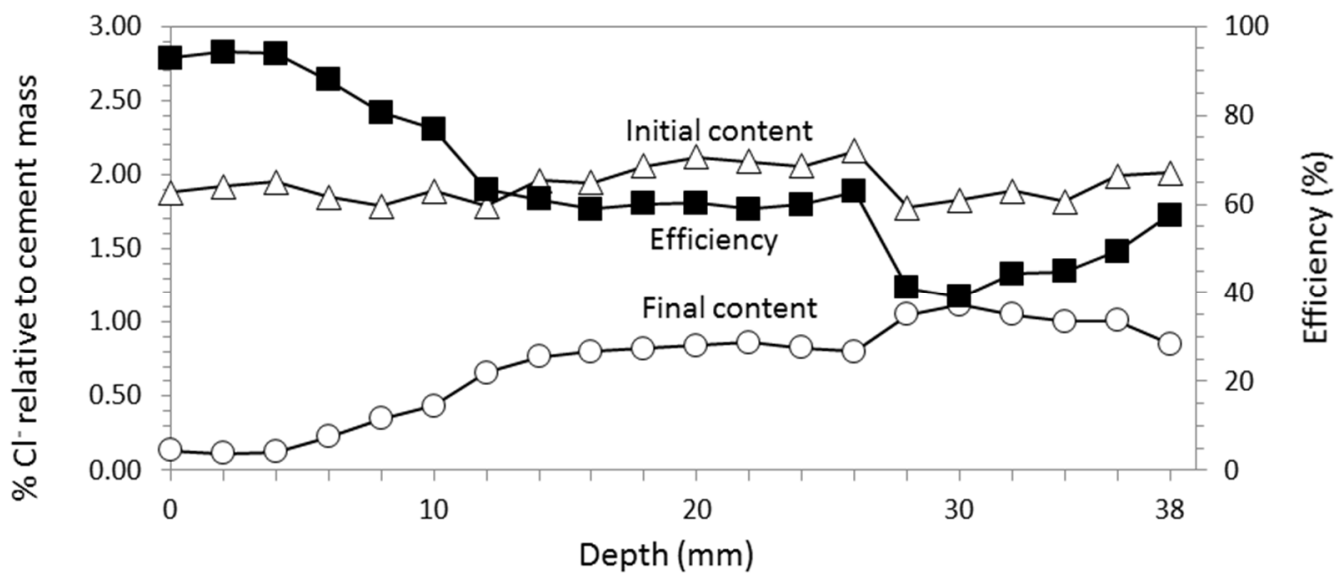

Figure 11. ECE with GCP anode. Rectangular section reinforced concrete specimen. Core extracted in the center of the biggest face of the specimen (position 1 in Figure 2). $\mathrm{Cl}^{-}$content profiles before and after ECE and distribution of local ECE efficiencies. Adapted from [24]. 


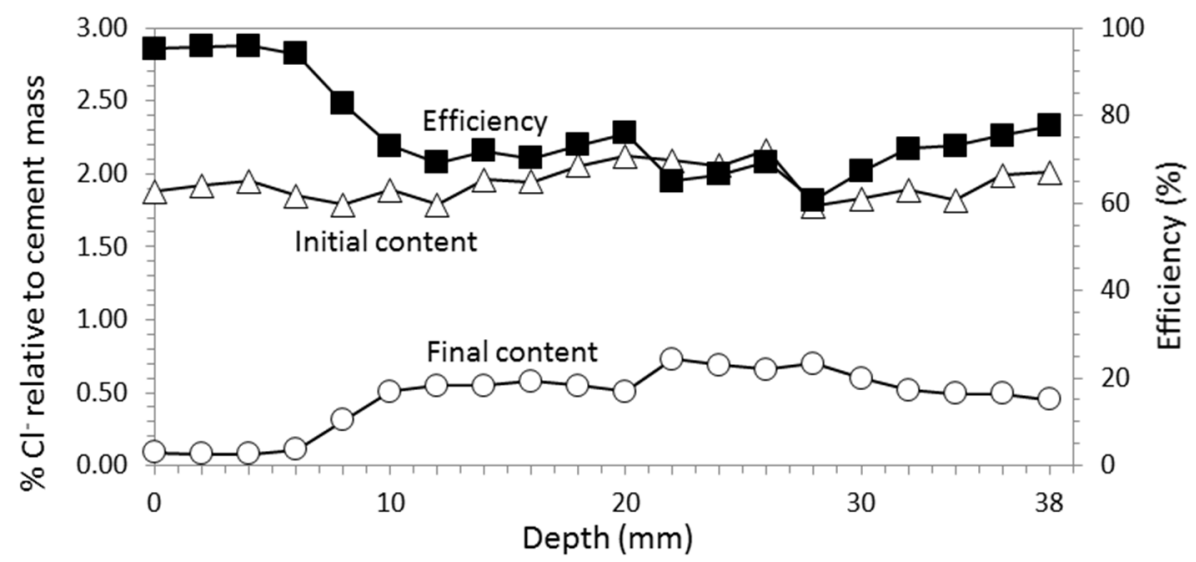

Figure 12. ECE with GCP anode. Rectangular section reinforced concrete specimen. Core extracted in the cover zone over the steel (position 2 in Figure 2). $\mathrm{Cl}^{-}$content profiles before and after ECE and distribution of local ECE efficiencies. Adapted from [24].

Table 6. Summary of obtained average efficiencies in the different tests carried out applying ECE to reinforced concrete specimens.

\begin{tabular}{ccccc}
\hline Trial & $\begin{array}{c}\text { Horizontal Section } \\
\text { of Specimen }\end{array}$ & Anode System & Core Sample Location & $\begin{array}{c}\text { Average } \\
\text { Efficiency (\%) }\end{array}$ \\
\hline 1 & Circular section & $\mathrm{Ti}-\mathrm{RuO}_{2}$ & - & 82.8 \\
2 & Circular section & $\mathrm{GCP}$ & - & 82.6 \\
3 & Rectangular section & $\mathrm{Ti}^{-\mathrm{RuO}_{2}}$ & Center of the biggest face & 52.5 \\
4 & Rectangular section & $\mathrm{Ti-} \mathrm{RuO}_{2}$ & Concrete cover over steel & 85.2 \\
5 & Rectangular section & $\mathrm{GCP}$ & Center of the biggest face & 64.4 \\
6 & Rectangular section & $\mathrm{GCP}$ & Concrete cover over steel & 76.2 \\
\hline
\end{tabular}

Regarding the specimens with rectangular sections and no uniformly distributed rebar (anisotropic element), the different ECE efficiencies obtained at different sampling positions of the concrete surface can be ascribed to differences in the electric flow density at those positions, confirming the hypothesis. Indeed, the experiments carried out with a $\mathrm{Ti}^{-\mathrm{RuO}_{2}}$ anode gave significantly different ECE efficiencies: $52.5 \%$ for the center of the biggest face versus $85.2 \%$ for the concrete cover over the rebar. The same effect was detected for the GCP anode, but the difference in ECE efficiency was significantly lower than that found for the Ti- $\mathrm{RuO}_{2}$ anode system (Table 6). This effect could be related to the different nature of both anodic systems. There is some difficulty in obtaining a good contact between the $\mathrm{Ti}-\mathrm{RuO}_{2}$ mesh anodic system and the concrete surface, because of the rigidity and elasticity of the metal mesh [8]. On the other hand, the GCP coating probably provided a good electrolytic contact with the concrete surface, thus avoiding the appearance of zones of high electric resistance, which can be responsible for low ECE efficiency. This quality, coupled with the fact that the cost of the GCP materials is 8-10 times lower than that of the Ti- $\mathrm{RuO}_{2}$ mesh, confirms GCP as a suitable anode system for ECE treatments.

\subsection{Case Study 3: Ability of the GCP Anode System to Apply CP, CPrev, and Combined ECE-CP Treatments}

In this section we describe the tests carried out to investigate the possibility of using the GCP anodes for applying protective electrochemical treatments to reinforced concrete elements affected by steel corrosion due to chloride contamination, such are CP, CPrev, and combined treatments of ECE plus $\mathrm{CP}$ or CPrev. The possibility of keeping the GCP anodes as permanent concrete coatings allows the subsequent application of a temporary treatment like ECE, for reducing an excessive $\mathrm{Cl}^{-}$content, followed by a permanent protection like $\mathrm{CP}$, in cases of exposure of the structure to a very aggressive chloride environment. Refer to Section 2.2 for experimental details. 
Figures 13 and 14 show the evolution of the open-circuit $E_{\text {corr }}$ values for the specimens of Table 3 during the duration of the first phase of the $\mathrm{CP}$ or CPrev experiments (24 weeks). In a similar manner,

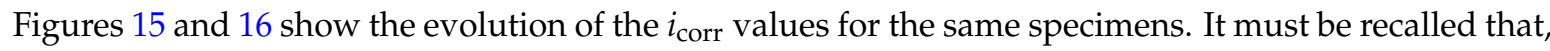
during the 24-week treatments, all specimens were subjected to an intense chloride loading regime (weekly sprayed applications of $65 \mathrm{~mL}$ of $\mathrm{NaCl} 0.5 \mathrm{M}$ ).

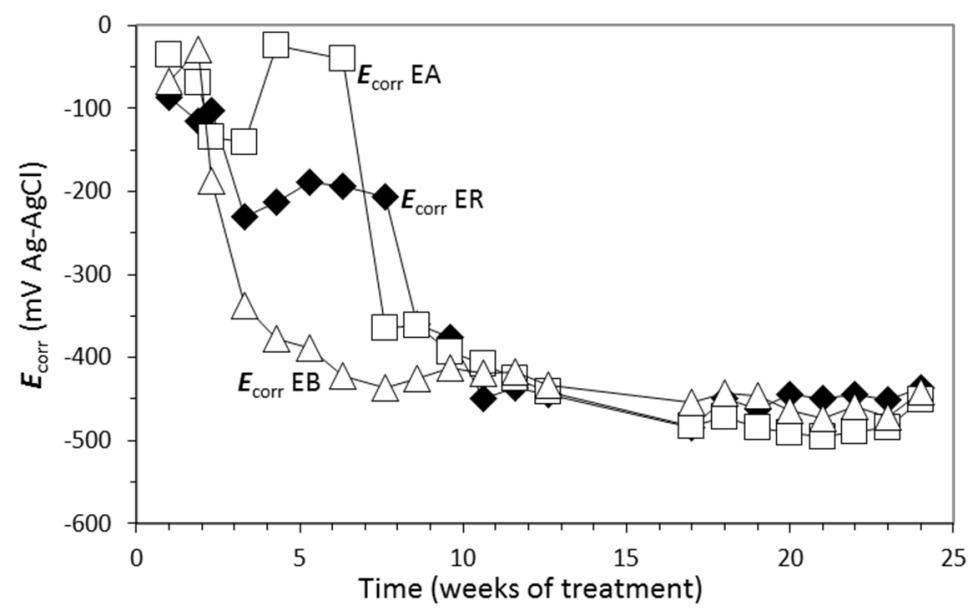

Figure 13. Evolution of $E_{\mathrm{corr}}$ during the treatments post ECE. EA: ECE+CP; EB: ECE+CPrev; ER: treated only with ECE. All of them were subjected to $\mathrm{Cl}^{-}$contamination during the 24 weeks. Current density values: CP: $15 \mathrm{~mA} / \mathrm{m}^{2}$, CPrev: $2 \mathrm{~mA} / \mathrm{m}^{2}$, both related to exposed concrete surface. Adapted from [27].

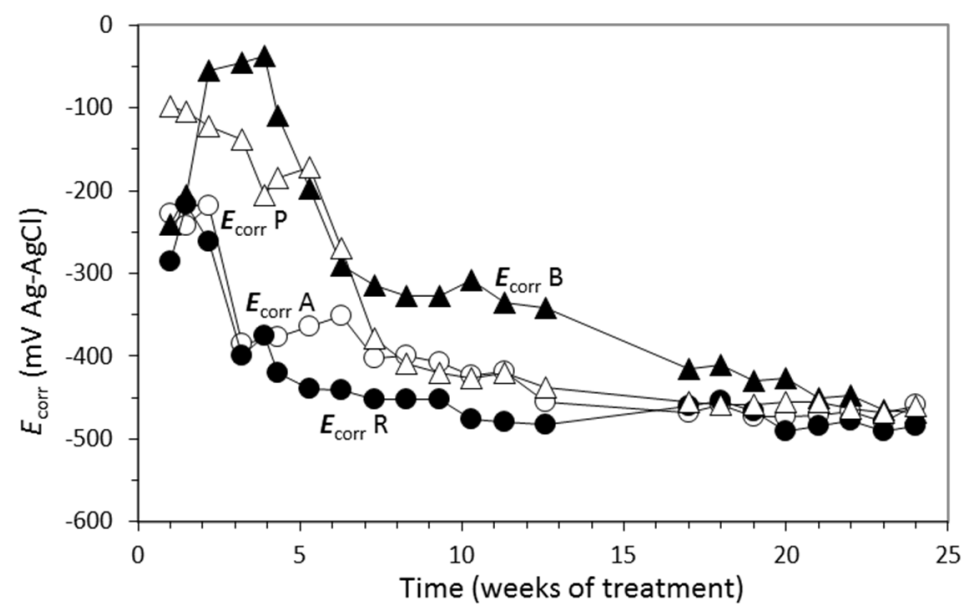

Figure 14. Evolution of $E_{\text {corr }}$ during the $\mathrm{CP}$ and $\mathrm{CPrev}$ treatments, without previous ECE. A: CP; B: CPrev; $\mathrm{R} \mathrm{(2 \%} \mathrm{Cl}{ }^{-}$in the mix, not $\mathrm{CP}$ treated): reference specimen for $\mathrm{A} ; \mathrm{P}$ (no $\mathrm{Cl}^{-}$in the mix, not $\mathrm{CPrev}$ treated): reference specimen for $\mathrm{B}$. All of them were subjected to $\mathrm{Cl}^{-}$contamination during the 24 weeks. Current density values: CP: $15 \mathrm{~mA} / \mathrm{m}^{2}$, CPrev: $2 \mathrm{~mA} / \mathrm{m}^{2}$, both related to exposed concrete surface. Adapted from [27].

For the three specimens previously treated with ECE, Figure 13 shows that the initial $E_{\text {corr }}$ values were equal or higher than $-100 \mathrm{mV}$, typical values of steel corrosion potentials after ECE [6]. The $E_{\mathrm{corr}}$ values of $\mathrm{EB}(\mathrm{ECE}+\mathrm{CPrev})$ quickly fell to values below $-400 \mathrm{mV}$; for six weeks the EA specimen $(\mathrm{ECE}+\mathrm{CP})$ remained at about $-100 \mathrm{mV}$, finally falling below $-400 \mathrm{mV}$ after 10 weeks; the reference specimen ER (only treated with ECE) showed an intermediate behaviour, falling to values of about $-200 \mathrm{mV}$ and finally reaching values below $-400 \mathrm{mV}$ after 11 weeks. It seems that a CP treatment with current density of $15 \mathrm{~mA} / \mathrm{m}^{2}$ (EA) was able to maintain protective conditions for steel for about 10 weeks despite the high chloride loading. On the other hand, CPrev treatment of $2 \mathrm{~mA} / \mathrm{m}^{2}$ (EB) was 
not able to provide protective conditions. This was expected since such low current density values are only effective for preventative treatments of reinforced concrete not previously contaminated with chlorides $[25,26]$, while the three specimens of Figure 13 started the 24-week trials with an initial $\mathrm{Cl}^{-}$ content of about $1 \%$ (relative to cement mass). Indeed, ECE was applied to specimens manufactured with $2 \% \mathrm{Cl}^{-}$relative to cement mass. With the previously described conditions, ECE was able to reduce the $\mathrm{Cl}^{-}$content of the specimens to approximately $51 \%$ of their initial content (51\% averaged ECE efficiency).

The evolution of the $E_{\text {corr }}$ values of the specimens not previously treated with ECE, Figure 14, shows that in this case the $\mathrm{CP}$ treatment with $15 \mathrm{~mA} / \mathrm{m}^{2}$ current density (A) was not able to protect steel from corrosion, since the corrosion potential of steel in A reached values below $-400 \mathrm{mV}$ in two weeks, and its values were only slightly higher than those of the non-CP-treated reference specimen (R). This different behavior, when compared to the observations of the precedent paragraph, can be explained by taking into account that the $\mathrm{A}$ and $\mathrm{R}$ specimens started the 24-week experiments with an initial $\mathrm{Cl}^{-}$content of $2 \%$ (relative to cement mass). To this must be added the large progressive $\mathrm{Cl}^{-}$contamination due to the weekly salting regime. On the other hand, the CPrev treatment with $2 \mathrm{~mA} / \mathrm{m}^{2}$ current density, given to the initially $\mathrm{Cl}^{-}$free specimen (B) allowed it to maintain values of $E_{\text {corr }}$ higher than $-400 \mathrm{mV}$, and clearly higher than those corresponding to the non-CPrev-treated reference specimen $(\mathrm{P})$, up to the current interruption at the 13th week. This is a further confirmation of the tolerance increase to chloride-induced corrosion for $\mathrm{CPrev}$ treated steel (current densities in the range $0.5-2 \mathrm{~mA} / \mathrm{m}^{2}$ of concrete surface). These low cathodic currents, applied from the beginning of the service life of a reinforced concrete structure, decrease the steel potential, thus leading to important increases in the critical chloride content for pitting corrosion of steel $[25,26]$.

From the observation of the evolution of the steel corrosion rates during the 24-week treatments (Figures 15 and 16), little difference appears between the behavior of the treated specimens (EA, EB, A, B) and their corresponding reference specimens (ER, R, P). Furthermore, in all cases $i_{\text {corr }}$ values higher than $0.1-0.2 \mu \mathrm{A} / \mathrm{cm}^{2}$ were obtained, which means that in no case was a repassivation of steel obtained in open-circuit conditions. A correct interpretation of these observations needs to consider that most of the tested specimens had experienced corrosion before starting the treatments, since the concrete was admixed with $2 \% \mathrm{Cl}^{-}$relative to cement mass; and all the specimens were subjected to a severe chloride load during the 24-week treatments. In these conditions it is practically impossible to obtain a permanent repassivation of steel with temporary electrochemical rehabilitation methods [44,45]; even $\mathrm{CP}$ or CPrev treatments need to be continuously applied for maintaining the protective conditions for steel.

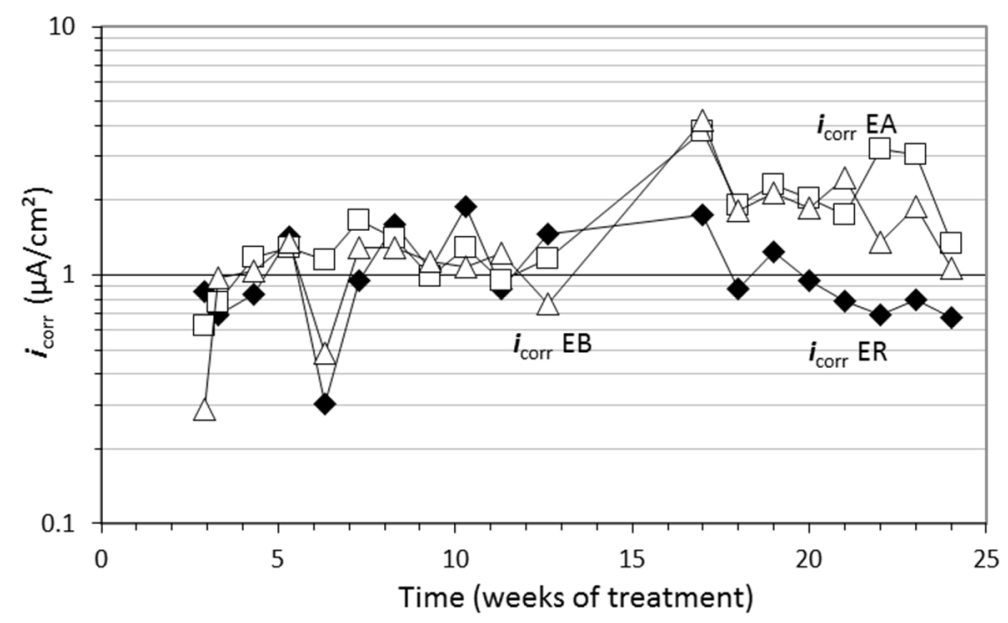

Figure 15. Evolution of $i_{\text {corr }}$ during the treatments post ECE. EA: ECE+CP; EB: ECE+CPrev; ER: treated only with ECE. All of them were subjected to $\mathrm{Cl}^{-}$contamination during the 24 weeks. Current density values: CP: $15 \mathrm{~mA} / \mathrm{m}^{2}$, CPrev: $2 \mathrm{~mA} / \mathrm{m}^{2}$, both related to exposed concrete surface. Adapted from [27]. 


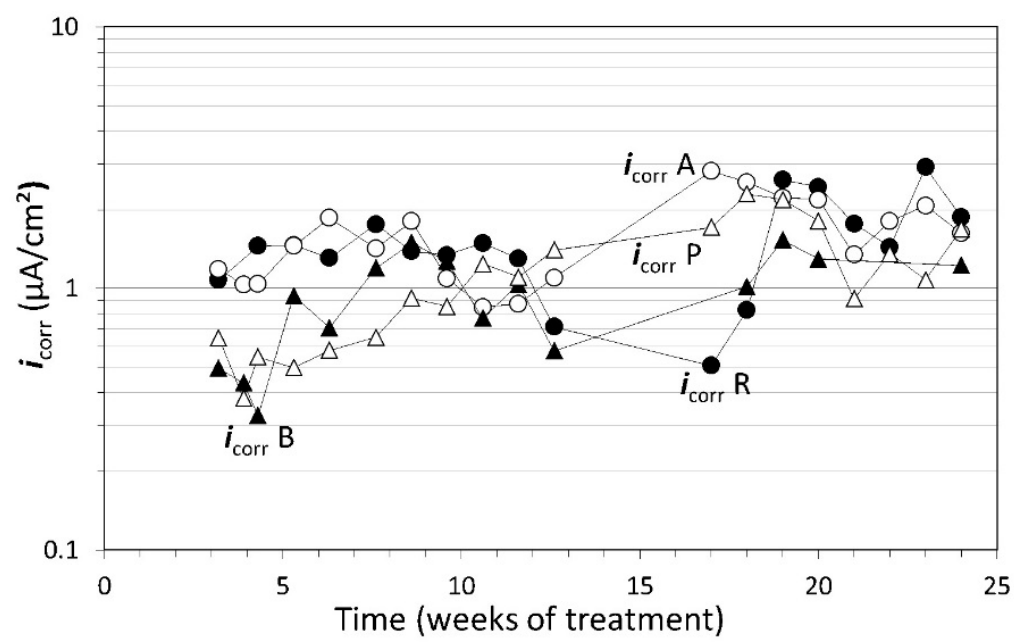

Figure 16. Evolution of $i_{\text {corr }}$ during the $\mathrm{CP}$ and $\mathrm{CPrev}$ treatments, without previous ECE. A: CP; B: CPrev; $\mathrm{R}\left(2 \% \mathrm{Cl}^{-}\right.$in the mix, not $\mathrm{CP}$ treated): reference specimen for $\mathrm{A} ; \mathrm{P}$ (no $\mathrm{Cl}^{-}$in the mix, not CPrev treated): reference specimen for $\mathrm{B}$. All of them were subjected to $\mathrm{Cl}^{-}$contamination during the 24 weeks. Current density values: CP: $15 \mathrm{~mA} / \mathrm{m}^{2}$, CPrev: $2 \mathrm{~mA} / \mathrm{m}^{2}$, both related to exposed concrete surface. Adapted from [27].

To verify the effectiveness of $\mathrm{CP}$ and $\mathrm{CPrev}$ treatments for protecting steel from corrosion, the "100 mV decay" criterion [41] was used, as stated in Section 2.2.4. Figure 17 shows the evolution of the $\Delta E_{\text {decay }}$ values for all the specimens in Table 3 during the 24-week experiments. Regarding the EA specimen $(\mathrm{ECE}+\mathrm{CP})$, the protection conditions of steel were kept steady for 11 weeks because of cathodic current circulation, despite external $\mathrm{Cl}^{-}$loading. On the other hand, the $\Delta E_{\text {decay }}$ values of the A specimen (CP only) practically never reached the threshold value of $100 \mathrm{mV}$. These observations

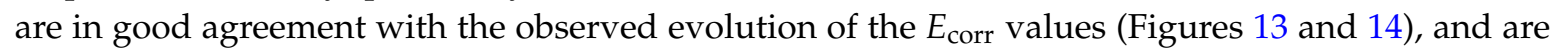
evidence that cathodic protection of $15 \mathrm{~mA} / \mathrm{m}^{2}$ current density (relative to concrete surface) is able to stabilise protective conditions for the steel reinforcement if the initial $\mathrm{Cl}^{-}$content of the specimen is about $1 \%$ (EA). In the case of the specimen with an initial $\mathrm{Cl}^{-}$content of about $2 \%(\mathrm{~A})$, a higher current density would be needed for reaching the protection conditions.

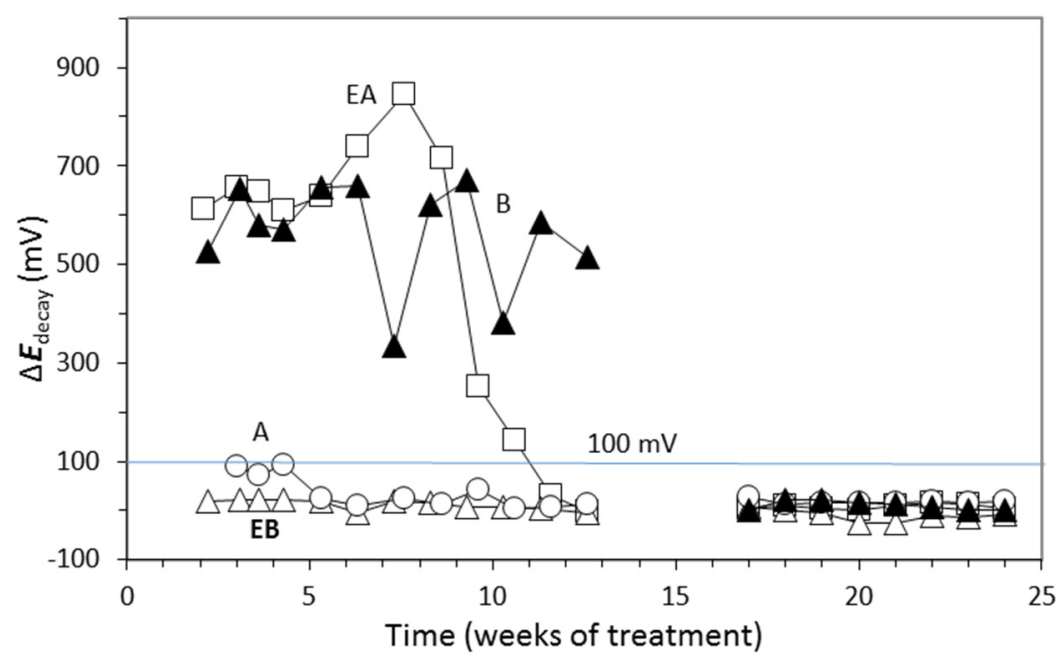

Figure 17. Evolution of $\Delta E_{\text {decay }}$ during the $\mathrm{CP}$ or CPrev treatments. A: CP; B: CPrev; EA: ECE+CP; EB: $\mathrm{ECE}+\mathrm{CPrev}$. All of them were subjected to $\mathrm{Cl}^{-}$contamination during the 24 weeks. The electrochemical treatments were interrupted between week 13 and week 17. Adapted from [27]. 
Regarding the CPrev treated specimens (cathodic current density $2 \mathrm{~mA} / \mathrm{m}^{2}$ relative to concrete surface), Specimen B showed $\Delta E_{\text {decay }}$ values higher than $100 \mathrm{mV}$ up to the current switch off at the 13th week, confirming the capacity of continuously applied CPrev treatments to keep steel protection conditions for an initially $\mathrm{Cl}^{-}$-free reinforced concrete, despite extensive external $\mathrm{Cl}^{-}$load $[25,26,46,47]$. On the other hand, such a low current density is unable to protect steel if concrete is previously contaminated at a level of about $1 \%$ relative to cement mass, as shown for specimen EB (ECE+CPrev) in Figure 17.

Given that after 24 weeks of treatments, including rest periods between the 13th and 17th weeks, the reinforcements had completely lost their protection conditions, and a $\mathrm{CP}$ of $15 \mathrm{~mA} / \mathrm{m}^{2}$ was unable to restore the protective conditions (Figure 17), the second phase was started. The external $\mathrm{Cl}^{-}$load was discontinued since all the specimens had reached very high $\mathrm{Cl}^{-}$contents (see Table 7).

Table 7. Final averaged chloride contents (expressed in $\% \mathrm{Cl}^{-}$relative to cement mass) at the end of 24 weeks of exposure to a severe $\mathrm{Cl}^{-}$load (first phase of $\mathrm{CP}$ and $\mathrm{CPrev}$ treatments).

\begin{tabular}{|c|c|c|c|c|}
\hline Specimen & $\begin{array}{l}\text { Initial } \mathrm{Cl}^{-} \text {Content } \\
\text { (\% ref. cem. mass) }\end{array}$ & $\begin{array}{c}\text { Electrochemical } \\
\text { Treatment Previous to } \\
\text { the 24-week First Phase }\end{array}$ & $\begin{array}{l}\text { Electrochemical } \\
\text { Treatment during the } \\
\text { 24-week First Phase }\end{array}$ & $\begin{array}{c}\text { Final Averaged }{ }^{*} \\
\mathrm{Cl}^{-} \text {Content } \\
\text { (\% ref. cem. mass) }\end{array}$ \\
\hline $\mathrm{R}$ & 2 & - & - & 6.08 \\
\hline ER & 2 & ECE & - & 4.26 \\
\hline A & 2 & - & $\mathrm{CP}$ & 5.39 \\
\hline $\mathrm{EB}$ & 2 & ECE & CPrev & 3.42 \\
\hline
\end{tabular}

* The final $\mathrm{Cl}^{-}$content was calculated as the mean value of those found in the $\mathrm{Cl}^{-}$content profile determined through the concrete cover zone (20 mm width).

In these conditions, $\mathrm{CP}$ was applied with higher current densities. The question was if it would be possible to recover the protection conditions of steel by increasing the current density to the appropriate value. In the beginning of this last phase, current density was set at $20 \mathrm{~mA} / \mathrm{m}^{2}$. After four weeks of operation $100 \mathrm{mV}$ of $\Delta E_{\text {decay }}$ was not reached, i.e. the protection conditions were not obtained (Figure 18). Neither was success obtained in a second attempt with $25 \mathrm{~mA} / \mathrm{m}^{2}$ (data not shown in Figure 18). Finally, a third step of $40 \mathrm{~mA} / \mathrm{m}^{2}$ was set. In this case, after four weeks, the rule of $100 \mathrm{mV}$ of $\Delta E_{\text {decay }}$ was achieved for $\mathrm{EA}, \mathrm{A}$, and $\mathrm{B}$ specimens.

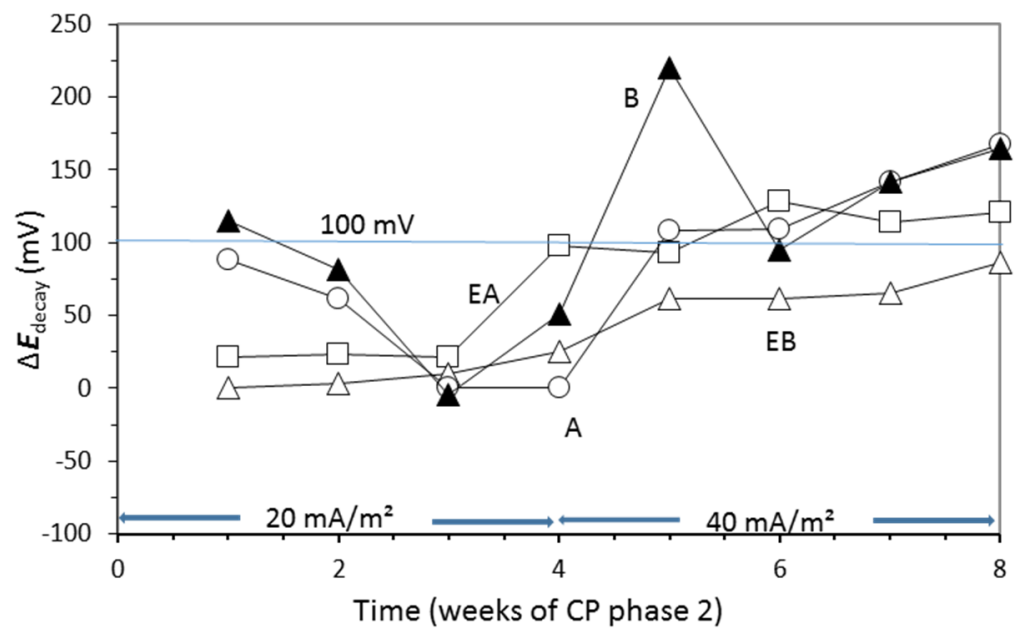

Figure 18. Evolution of $\Delta E_{\text {decay }}$ during Phase 2 of CP. First step of four weeks with $20 \mathrm{~mA} / \mathrm{m}^{2}$ of current density, and third step with $40 \mathrm{~mA} / \mathrm{m}^{2}$. Specimens A, B, EA, and EB. Adapted from [27]. 
Moreover, protection conditions were verified with the measurement of depolarization potential difference values seven days after switch-off [41]. In fact, more than $150 \mathrm{mV}$ of $\Delta E_{\text {decay }}$ was reached after seven days ( $209 \mathrm{mV}$ for EA, $211 \mathrm{mV}$ for A and $153 \mathrm{mV}$ for B). This efficiency of CP is similar to that obtained by other researchers [10,42]. However, this was not the case for EB. After four weeks with the highest cathodic current density, the protection conditions were not recovered for this latter specimen.

\section{Conclusions}

Based on the results and observations obtained from this research, the following conclusions have been made:

1. For ECE treatments on structural concrete elements, including vertical or those of complex shape, the use of a GCP sprayed coating as anode is feasible, and achieves a similar efficiency (about $80 \%)$ to a conventional reference anode ( $\mathrm{Ti}-\mathrm{RuO}_{2}$ mesh) when passing a typical electric charge density of $5 \mathrm{MC} / \mathrm{m}^{2}$. Also, a substantial proportion of $\mathrm{Cl}^{-}$was removed with a low applied charge density, achieving $51 \%$ ECE efficiency at $1.5 \mathrm{MC} / \mathrm{m}^{2}$.

2. The results provide confirmation regarding the shape effect of the structural elements on the ECE efficiency. The typical spatial distribution of the steel rebar within certain concrete elements, for example vertical columns of the rectangular section, gives rise to an anisotropic configuration of the electric flow lines. This leads to variations in the local ECE efficiencies found at different sampling points for such types of reinforced concrete elements. The use of GCP anodes, rather than the more commonly employed $\mathrm{Ti}-\mathrm{RuO}_{2}$ mesh embedded between polymeric layers, appears to reduce the differences found in the local ECE efficiencies due to the shape effect. This may be due to the nature of the electrolytic contact between the GCP coating and the concrete surface, which may avoid possible zones of high electric resistance due to defective contact between the somewhat rigid and springy metal mesh anodic system and the concrete surface.

3. According to the results of the CP applied with a GCP coating as anode, this electrochemical technique is able to provide protection to steel, despite severe internal and external chloride contamination, provided an appropriate current density value is selected based on the $\mathrm{Cl}^{-}$ content present. Its ability to recover the lost protection conditions through an increase of current density has also been demonstrated.

4. Continuously applied CPrev (at a current density of $2 \mathrm{~mA} / \mathrm{m}^{2}$ ) with a GCP coating as anode is able to maintain a conventional, initially $\mathrm{Cl}^{-}$-free concrete in a protection condition despite being exposed to a severe $\mathrm{Cl}^{-}$load. However, subject to the same experimental external chloride load, it is unable to recover protection conditions if the initial $\mathrm{Cl}^{-}$content is equal to or higher than $1 \%$ relative to cement mass.

5. A GCP coating allows the application of a combined treatment of ECE followed by $\mathrm{CP}$, changing only the current density provided by the DC power source. No damage was observed in this anode after the full combined process. This combination has been shown to be capable of maintaining or recovering protection conditions if the cathodic current density is set to the appropriate value according to the $\mathrm{Cl}^{-}$content present.

6. Given the novel nature of the GCP coating and its relatively short track record, it is recommended that further research is carried out to assess the GCP coating in a range of operating conditions to fully ascertain its suitability for practical applications.

Acknowledgments: This research was funded by the Spanish Ministerio de Economía y Competitividad (and formerly by the Spanish Ministerio de Ciencia e Innovación) and ERDF (European Regional Development Fund) through projects BIA2010-20548 and MAT2009-10866, and also through the project PROMETEO/2013/035 of Generalitat Valenciana (Spain).

Author Contributions: J. Carmona performed the experiments in the framework of his Ph.D. thesis, co-supervised by P. Garcés and M.A. Climent, and contributed to the redaction of the article; P. Garcés conceived the idea of using GCP coatings for different applications (multifunctional material concept), the method of application of 
the coatings, and details of the ECE experiments; M.A. Climent conceived the methods for determining the ECE efficiencies and the experiments on $\mathrm{CP}$ and $\mathrm{CPrev}$, and contributed to the redaction of the article. The analysis of data was performed by the whole team.

Conflicts of Interest: The authors declare no conflict of interest.

\section{References}

1. Lankard, D.R.; Slater, J.E.; Hedden, W.A.; Niesz, D.E. Neutralization of Chloride in Concrete. In Battelle Columbus Laboratories; Report No. FHWA-RD-76-60; Federal Highway Administration: Washington, DC, USA, 1975; p. 143.

2. Slater, J.E.; Lankard, D.R.; Moreland, P.J. Electrochemical removal of chlorides from concrete bridge decks. Mater. Perform. 1976, 15, 21-26.

3. Tritthart, J. Electrochemical Chloride Removal: An Overview and Scientific Aspects; The American Ceramic Society: Westerville, OH, USA, 1998; pp. 401-441.

4. Mietz, J. Electrochemical Rehabilitation Methods for Reinforced Concrete Structures: A State of the Art Report. In Publication Number 24 of the European Federation of Corrosion; IOM Communications Ltd.: London, UK, 1998; p. 57.

5. Andrade, C.; Castellote, M.; Alonso, C. An overview of electrochemical realkalisation and chloride extraction. In Rehabilitation of Structures, Proceedings of 2nd International RILEM/CSIRO/ACRA Conference, Melbourne, Australia, 21-23 September 1998; Ho, D.W.S., Godson, I., Collins, F., Eds.; RILEM: Melbourne, Australia, 1998; pp. 1-12.

6. Pedeferri, P.; Bertolini, L. La Durabilità del Calcestruzzo Armato; McGraw-Hill: Milano, Italy, 2000. (In Italian)

7. Bertolini, L.; Elsener, B.; Pedeferri, P.; Polder, R. Corrosion of Steel in Concrete; Wiley-Vch.: Weinheim, Germany, 2004.

8. Climent, M.A.; Sánchez de Rojas, M.J.; de Vera, G.; Garcés, P. Effect of type of anodic arrangements on efficiency of electrochemical chloride removal from concrete. ACI Mater. J. 2006, 103, 243-250.

9. Glass, G.K.; Chadwick, J.R. An investigation into the mechanisms of protection afforded by a cathodic current and the implications for advances in the field of cathodic protection. Corros. Sci. 1994, 36, 2193-2209. [CrossRef]

10. Christodoulou, C.; Glass, G.; Webb, J.; Austin, S.; Goodier, C. Assessing the long term benefits of impressed current cathodic protection. Corros. Sci. 2010, 52, 2671-2679. [CrossRef]

11. Fu, X.; Chung, D.D.L. Carbon fiber reinforced mortar as an electrical contact material for cathodic protection. Cem. Concr. Res. 1995, 25, 689-694. [CrossRef]

12. Hou, J.; Chung, D.D.L. Cathodic protection of steel reinforced concrete facilitated by using carbon fiber reinforced mortar or concrete. Cem. Concr. Res. 1997, 27, 649-656. [CrossRef]

13. DePeuter, F.; Lazzari, L. New conductive overlay for CP in concrete: Results of long term testing. In Proceedings of Corrosion/93-National Association of Corrosion Engineers Annual Conference, New Orleans, LA, USA, 7-12 March 1993; no. 325.

14. Bertolini, L.; Bolzoni, F.; Pastore, T.; Pedeferri, P. Effectiveness of a conductive cementitious mortar anode for cathodic protection of steel in concrete. Cem. Concr. Res. 2004, 34, 681-694. [CrossRef]

15. Chung, D.D.L. Electrically conductive cement-based materials. Adv. Cem. Res. 2004, 16, 167-176. [CrossRef]

16. Garcés, P.; Fraile, J.; Vilaplana-Ortego, E.; Cazorla, D.; Alcocel, E.G.; Andión, L.G. Effects of carbon fibres on the mechanical properties and corrosion levels of reinforced Portland cement mortars. Cem. Concr. Res. 2005, 35, 324-331. [CrossRef]

17. Garcés, P.; Andión, L.G.; de la Varga, I.; Catalá, G.; Zornoza, E. Corrosion of steel reinforcement in structural concrete with carbon material addition. Corros. Sci. 2007, 49, 2557-2566. [CrossRef]

18. Zornoza, E.; Catalá, G.; Jiménez, F.; Andión, L.G.; Garcés, P. Electromagnetic interference shielding with Portland cement paste containing carbon materials and processed fly ash. Mater. Constr. 2010, 60, 21-32.

19. Garcés, P.; Zornoza, E.; Alcocel, E.G.; Galao, Ó.; Andión, L.G. Mechanical properties and corrosion of CAC mortars with carbon fibers. Constr. Build. Mater. 2012, 34, 91-96. [CrossRef]

20. Han, B.; Yu, X.; Ou, J. Multifunctional and Smart Carbon Nanotube Reinforced Cement-Based Materials. In Nanotechnology in Civil Infrastructure: A Paradigm Shift; Gopalakrishnan, K., Birgisson, B., Taylor, P., Attoh-Okine, N.O., Eds.; Springer: Berlin, Heidelberg, Germany, 2011; pp. 1-47. 
21. Pérez, A.; Climent, M.A.; Garcés, P. Electrochemical extraction of chlorides from reinforced concrete using a conductive cement paste as the anode. Corros. Sci. 2010, 52, 1576-1581. [CrossRef]

22. Cañón, A.; Garcés, P.; Climent, M.A.; Carmona, J.; Zornoza, E. Feasibility of electrochemical chloride extraction from structural reinforced concrete using a sprayed conductive graphite powder-cement as anode. Corros. Sci. 2013, 77, 128-134. [CrossRef]

23. Garcés, P.; Sánchez de Rojas, M.J.; Climent, M.A. Effect of the reinforcement bar arrangement on the efficiency of electrochemical chloride removal technique applied to the reinforced concrete structures. Corros. Sci. 2006, 48, 531-545. [CrossRef]

24. Carmona, J.; Climent, M.A.; Antón, C.; de Vera, G.; Garcés, P. Shape effect of electrochemical chloride extraction in structural reinforced concrete elements using a new cement-based anodic system. Materials 2015, 8, 2901-2917. [CrossRef]

25. Pedeferri, P. Cathodic protection and cathodic prevention. Constr. Build. Mat. 1996, 10, 391-402. [CrossRef]

26. Bertolini, L.; Bolzoni, F.; Pedeferri, P.; Lazzari, L.; Pastore, T. Cathodic protection and cathodic prevention in concrete principles and applications. J. Appl. Electrochem. 1998, 28, 1321-1331. [CrossRef]

27. Carmona, J.; Garcés, P.; Climent, M.A. Efficiency of a conductive cement-based anodic system for the application of cathodic protection, cathodic prevention and electrochemical chloride extraction to control corrosion in reinforced concrete structures. Corros. Sci. 2015, 96, 102-111. [CrossRef]

28. Comisión Permanente del Hormigón. Instrucción de Hormigón Estructural EHE-08 (Spanish Code on Structural Concrete EHE-08); Ministerio de Fomento: Madrid, Spain, 2008. (In Spanish)

29. UNE EN 12390-3:2009 Ensayos de Hormigón Endurecido. Parte 3: Determinación de la Resistencia a Compresión de Probetas (Testing Hardened Concrete-Part 3: Compressive Strength of Test Specimens); Asociación Española de Normalización y Certificación AENOR: Madrid, Spain, 2009. (In Spanish)

30. UNE 83980:2014 Durabilidad del Hormigón. Métodos de Ensayo. Determinación de la Absorción de Agua, la Densidad y la Porosidad Accesible al Agua del Hormigón (Concrete Durability. Test Methods. Determination of the Water Absorption, Density and Accessible Porosity for Water in Concrete); Asociación Española de Normalización y Certificación AENOR: Madrid, Spain, 2014. (In Spanish)

31. UNE EN 12390-7:2009 Ensayos de HormigóN Endurecido. Parte 7: Densidad del Hormigón Endurecido (Testing Hardened Concrete-Part 7: Density of Hardened Concrete); Asociación Española de Normalización y Certificación AENOR: Madrid, Spain, 2009. (In Spanish)

32. CEN/TS 14038-2 Technical Specification. Electrochemical Re-alkalization and Chloride Extraction Treatments for Reinforced Concrete-Part 2: Chloride Extraction; European Committee of Standardization CEN: Brussels, Belgium, 2011.

33. Elsener, B.; Molina, M.; Böhni, H. The electrochemical removal of chlorides from reinforced concrete. Corros. Sci. 1993, 35, 1563-1570. [CrossRef]

34. Elsener, B.; Angst, U. Mechanism of electrochemical chloride removal. Corros. Sci. 2007, 49, 4504-4522. [CrossRef]

35. Sánchez de Rojas, M.J.; Garcés, P.; Climent, M.A. Electrochemical extraction of chlorides from reinforced concrete: variables affecting treatment efficiency. Mater. Constr. 2006, 56, 17-26.

36. Vennesland, Ø.; Climent, M.A.; Andrade, C. Recommendation of RILEM TC 178-TMC: Testing and modeling chloride penetration in concrete. Methods for obtaining dust samples by means of grinding concrete in order to determine the chloride concentration profile. Mater. Struct. 2013, 46, 337-344.

37. Climent, M.A.; Viqueira, E.; de Vera, G.; López, M.M. Analysis of acid-soluble chloride in cement, mortar and concrete by potentiometric titration without filtration steps. Cem. Concr. Res. 1999, 29, 893-898. [CrossRef]

38. Climent, M.A.; de Vera, G.; Viqueira, E.; López, M.M. Generalization of the possibility of eliminating the filtration step in the determination of acid-soluble chloride content in cement and concrete by potentiometric titration. Cem. Concr. Res. 2004, 34, 2291-2295. [CrossRef]

39. Galao, O.; Baeza, F.J.; Zornoza, E.; Garcés, P. Strain and damage sensing properties on multifunctional cement composites with CNF. Cem. Concr. Comp. 2014, 46, 90-98. [CrossRef]

40. Andrade, C.; Alonso, C.; Gulikers, J.; Polder, R.; Cigna, R.; Vennesland, Ø.; Salta, M. Test methods for on-site reinforcement corrosion rate measurement of steel reinforcement in concrete by means of the Polarization Resistance method. RILEM Recommendation of TC-154. Electrochemical Techniques for measuring metallic corrosion. Mater. Struct. 2004, 37, 623-643. [CrossRef]

41. ISO 12696: 2012(en) Cathodic Protection of Steel in Concrete; ISO: Geneva, Switzerland, 2012. 
42. Glass, G.K.; Hassanein, A.M.; Buenfeld, N.R. Cathodic protection afforded by an intermittent current applied to reinforced concrete. Corros. Sci. 2001, 43, 1111-1131. [CrossRef]

43. Pellegrini-Cervantes, M.J.; Barrios-Durstewitz, C.P.; Núñez-Jaquez, R.E.; Almeraya-Calderón, F.; Rodríguez-Rodríguez, M.; Castorena-González, J.H.; Garcés-Velázquez, E.; Maldonado-Bandala, E.E.; Nieves-Mendoza, D.; García-Contreras, J.P. Conductive cement pastes with carbon fibers as anodes in the electrochemical chloride extraction. Int. J. Electrochem. Sci. 2015, 10, 3830-3840.

44. Miranda, J.M.; González, J.A.; Cobo, A.; Otero, E. Several questions about electrochemical rehabilitation methods for reinforced concrete structures. Corros. Sci. 2006, 48, 2172-2188. [CrossRef]

45. Miranda, J.M.; Cobo, A.; Otero, E.; González, J.A. Limitations and advantages of electrochemical chloride removal in corroded reinforced concrete structures. Cem. Concr. Res. 2007, 37, 596-603. [CrossRef]

46. Liu, Y.; Shi, X. Modeling cathodic prevention for unconventional concrete in salt-laden environment. Anti-Corros. Methods Mater. 2012, 59, 121-131. [CrossRef]

47. Dugarte, M.; Sagüés, A.A.; Williams, K. Cathodic prevention for reinforcing steel in cracked concrete of chloride contaminated structures. In Proceedings of CORROSION 2015 Conference, NACE-2015-6102, NACE International, Houston, TX, USA, 15-19 March 2015; p. 11.

(C) 2016 by the authors; licensee MDPI, Basel, Switzerland. This article is an open access article distributed under the terms and conditions of the Creative Commons Attribution (CC-BY) license (http://creativecommons.org/licenses/by/4.0/). 